Universidade de São Paulo

Instituto de Física

\title{
Estudo experimental da eletrocomunicação em peixes de campo elétrico fraco da espécie Gymnotus carapo - uma aplicação da Teoria da Informação
}

\author{
Caroline Garcia Forlim \\ Orientador: Reynaldo Daniel Pinto
}

Dissertação de mestrado apresentada ao Instituto de Física para a obtenção do título de Mestre em Ciências

Comissão Examinadora:

Prof. Dr. Angel Ariel Caputi- IIBCE-Uruguai

Profa. Dra. Coraci Pereira Malta - IFUSP Prof. Dr. Reynaldo Daniel Pinto-IFUSP 


\section{Agradecimentos}

Agradeço ao Prof. Reynaldo pela paciência de me ensinar, pelo apoio e pelas ótimas idéias, aos meus amigos do laboratório Bóris, Ludmila e Pedro pela ajuda, pelas discussões frutíferas e pelos cafés, ao Prof. Sartorelli pelo apoio e pelas risadas, à minha família pelo incentivo e por terem suportado meus ataques de mau humor e a todos que de alguma forma contribuíram para a realização deste trabalho.

Agradeço à FAPESP pelo apoio financeiro. 
À minha querida família 


\section{Resumo}

Construímos um aparato experimental para medir os instantes de disparo do órgão elétrico de peixes elétricos de campo fraco da espécie Gymnotus carapo, que produz estes pulsos para localizar objetos dentro da água e para se comunicar socialmente. $\mathrm{O}$ aparato foi desenvolvido de maneira a isolar o animal de perturbações externas como vibrações mecânicas, sons, campos elétricos e variações de luminosidade do ambiente.

A principal característica de nosso aparato é um conjunto de eletrodos, distribuídos nos vértices do tanque de experimentos, que permitem obter as medidas (longas séries de instantes de disparo) sem restringir os movimentos do peixe e até mesmo inferir a sua posição comparando as amplitudes em diferentes eletrodos, o que possibilita relacionar a posteriori os padrões de disparo ao comportamento do animal.

Desenvolvemos um programa de computador em linguagem $\mathrm{C}$ que, através de uma interface digital-analógica reproduz a série temporal da voltagem de um pulso de um peixe verdadeiro e utilizamos este sinal elétrico para estimular os animais. Os pulsos artificiais foram aplicados a um dipolo elétrico que imita a geometria do órgão elétrico de um peixe e os intervalos entre pulsos foram produzidos por diferentes distribuições: aleatória, intervalos gravados previamente do próprio ou de outro peixe, sequências manipuladas para repetir determinados trechos reais intercalados com trechos aleatórios, etc.

Um segundo computador foi utilizado para detectar os instantes dos pulsos de estímulo e resposta e armazenar estas sequências em arquivos. Posteriormente utilizamos estas sequências para calcular a informação mútua média entre os sinais e verificamos que diferentes peixes reconhecem e reagem (alterando seus disparos elétricos) a determinados trechos da série de estímulo real de maneira bastante reprodutível.

Também desenvolvemos outro programa de controle para detectar os pulsos do peixe em um dos aquários e estimular, em tempo real, o peixe de outro aquário e vice-versa. Assim, a única forma de interação entre os peixes é através dos pulsos elétricos e esta interação ocorre de modo bidirecional. Os dados destes experimentos também foram analisados utilizando o cálculo da informação mútua média entre os padrões dos dois peixes e encontramos evidências de que neste caso o fluxo de informação é maior que nos experimentos unidirecionais.

Nosso aparato permitiu utilizar com sucesso a teoria da informação para estudar a dinâmica de disparo durante a interação elétrica entre peixes e possibilita diversos experimentos futuros em que pretendemos relacionar os padrões elétricos ao comportamento social dos animais e a sua interação com o meio ambiente. 


\section{Abstract}

We built an experimental apparatus to measure the electric organ discharge times from weakly electric fishes of the Gymnotus carapo species. Such fishes use these pulses to actively locate objects in water as well as in social communication. Our apparatus was designed to allow such measures in the absence of some external perturbations the fishes are sensitive to, such as mechanical vibrations, electric fields and changes in the laboratory luminosity.

A set of eight electrods were installed in the corners of the experimental tank and allows to obtain the discharge times without need to restrain the movements of the fish. Actually, from the maximal amplitudes of the discharge in different elecrodes we can infer the position and movements of the fish and relate its electrical dynamics to its behavior.

A computer program (C language) was written to use a digital to analog interface to reproduce the time series of a discharge pulse from a real fish (recorded previously) and this electrical signal was used to stimulate the animals. The artificial pulses were applied to an electrical dipole built to mimic the geometry of the electrical organ of a living fish. The intervals between discharges were chosen from sequences obtained from different distributions: random, sequencies from real living fishes, handled sequencies where we repeated some real patterns with random patterns in between, etc.

The detection of the stimuli and response pulses were done in another computer with the software Dasylab and the discharge times sequencies were recorded in harddisk for further analysis. Both sequencies were used to compute the average mutual information between the signals and we verified that different fishes recognize and react (changing their pulse interval pattterns) to the same regions of the real stimuli sequence.

We also developed another control program (C language) to detect the discharges of a fish in one tank and to stimulate, in real time, a fish in another tank with those pulses, and vice-versa, in a bidirectional way. In this way, the only interaction between the fishes is through their electric pulses. The data analysis also consisted in obtaining the average mutual information between the sequencies of the two fishes and we found evidences that the flow of information is higher than that found in unidirectional experiments.

Our apparatus allowed us to succesfully apply information theory to study the dynamics of the discharge intervals when the fishes are interacting. In the future we intend to extensivelly use such experiments to relate the electrical patterns to social behavior and to the interaction of these fishes with their environment. 


\section{Sumário}

1 - Introdução 1

2 - O sistema de eletro-localização/comunicação do peixe Gymnotus carapo 4

3 - Metodologia $\quad 9$

3.1 - Animais utilizados nos experimentos 9

3.2 - Teoria da Informação

3.3 - Aquisição e análise de dados 11

4 - Desenvolvimento do aparato experimental $\quad 12$

$\begin{array}{ll}4.1 \text { - Aparato inicial } & 12\end{array}$

4.2 - Aparato final $\quad 13$

5 - Experimentos e análise de dados $\quad 20$

$\begin{array}{ll}5.1 \text { - Experimentos } & 20\end{array}$

5.2 - Medidas longas dos disparos de peixes na ausência de estímulos 20

5.3 - Medidas com estímulos aleatórios e realistas produzidos por computador 23

5.4 - Dois peixes interagindo remotamente por computador 30

6 - Conclusões e discussões $\quad 33$

7 - Referências $\quad 34$

8 - Apêndices $\quad 36$

A1 - Teoria da Informação 36

A2 - Método dos surrogados 38 


\section{1 - Introdução}

O sistema nervoso dos animais evoluiu de modo a resolver problemas muito complexos, relacionados com o adequado controle do comportamento em ambientes naturais multidimensionais, não-estacionários e muitas vezes imprevisíveis. O sistema nervoso é um dos sistemas mais complexos existentes na natureza. Esta complexidade é o resultado não apenas da interação de um grande número de elementos não-lineares e de uma sofisticada arquitetura de conexões, mas também da flexibilidade e plasticidade desses elementos. Por estes motivos, entender o funcionamento de um sistema nervoso, mesmo dos mais simples, constitui um gigantesco desafio e um enorme esforço neste sentido tem sido feito pela comunidade científica ao longo da história.

Apesar de toda esta complexidade, quase todas as informações sensoriais que o sistema nervoso processa e todos os comportamentos motores gerados pelos animais são codificados na forma de pulsos elétricos estereotipados, que são produzidos e transmitidos pelos neurônios. O caráter inerentemente complexo do sistema volta a se manifestar, entretanto, na maneira como estes pulsos se organizam em padrões (Rieke et al.,1997)

Desse modo, entender como uma informação sensorial é processada pelo sistema nervoso observando os padrões espaço-temporais presentes nos sinais elétricos produzidos pelos neurônios torna-se uma tarefa bastante árdua, pois é muito difícil saber exatamente o que está sendo codificado e qual o código utilizado, além disso, muitas vezes um mesmo estímulo pode produzir padrões de resposta diferentes (Mainen e Sejnowski, 1995).

Ao longo da história, diversos modelos têm sido utilizados no estudo do processamento de informação em redes neurais biológicas. Um desses modelos, que possui características peculiarmente interessantes e, por isso, tem sido muito intensamente estudado, é o sistema sensorial dos peixes elétricos de campo fraco (Bullock, 1999). Estes peixes utilizam um órgão elétrico (OE) especializado para produzir um campo elétrico pulsado ao redor de seu corpo. Objetos que estejam dentro deste campo alteram a corrente induzida em orgãos eletroreceptores que se distribuem por toda a epiderme do peixe. Desta maneira, o peixe constrói uma imagem elétrica de suas vizinhanças (Caputi e Budelli, 1995) e pode se locomover em condições precárias de iluminação, ter hábitos noturnos ou habitar águas turvas. Este processo de análise da região ao redor do peixe pela monitoração de um campo auto-produzido é chamado de eletrolocalização (Von der Emde, 1999). Além da eletrolocalização os peixes também utilizam seus orgãos elétricos para eletrocomunicação, quando se comunicam socialmente, identificam o sexo e o tamanho dos vizinhos e resolvem disputas territoriais (DeCoursey, 1993).

Com base na descarga (DOE ou "EOD" do termo inglês Electric Organ Discharge) de seus OE, os peixes elétricos podem ser classificados como pulsadores ou onduladores. Os pulsadores produzem uma descarga curta semelhante a um pulso, a intervalos relativamente longos e irregulares. Dependendo da espécie, um pulsador descarregará seu orgão elétrico desde poucas vezes por minuto até mais de 80 por segundo. Os onduladores descarregam numa frequência constante para produzir um campo elétrico de tipo semelhante à onda senoidal. Nos onduladores a regularidade dos intervalos de descarga é notável; é suficientemente estável para ser o mais acurado dos relógios biológicos, em alguns casos a precisão dos pulsos chega a fração de 
microssegundo (Moortgat et al., 1998). Dependendo da espécie, um ondulador descarregará cerca desde de 100 vezes por segundo até mais de 1.800 por segundo.

A eletrolocalização e a eletrocomunicação são mecanismos extremamente complicados, principalmente devido ao processamento de uma enorme quantidade de informação sensorial espaço-temporal pelo sistema nervoso do animal. Entretanto, o sinal elétrico produzido pelos peixes é fácil de ser detectado. São pouquíssimos os sistemas nervosos que permitem com uma medida simples e não invasiva acessar um sinal produzido por um sub-sistema interno complexo e altamente especializado. Entretando, estudar a eletrocomunicação e sua relação com o comportamento social de peixes elétricos interagindo em tempo real é uma tarefa bem difícil, principalmente devido aos problemas relacionados com a separação das descargas dos peixes quando estes se movem livremente (Westby, 1975).

Por este motivo, na maioria dos trabalhos encontrados na literatura em que se observa a resposta do peixe a estímulos elétricos, geralmente o peixe tem seus movimentos drasticamente restritos e o protocolo de estímulo é sempre unidirecional: padrões periódicos ou séries de dados gravadas previamente do próprio peixe ou de outros são apresentados para o peixe e este não exerce nenhuma interferência nos estímulos. Estas técnicas, embora muito úteis para estudar diversos comportamentos relacionados à eletrolocalização, não são adequadas para o estudo de estratégias de comunicação.

Assim, a base de nosso trabalho foi procurar maneiras de estudar $o$ comportamento dos peixes utilizando estímulos mais complexos (produzidos com a utilização de técnicas em tempo real), que se aproximassem mais daqueles à que os animais são submetidos durante seu comportamento normal e aplicar técnicas sistemáticas para quantificar a relação entre o estímulo e a resposta. Para isso, tivemos que desenvolver uma série de equipamentos que permitissem medir os sinais do peixe sem perturbá-lo enquanto este nadava livremente em um tanque enquanto outros equipamentos implementados permitiram estudar a interação entre dois peixes em tempo real. Paralelamente desenvolvemos uma série de programas de análise de dados baseados na aplicação de técnicas da Teoria da Informação.

A Teoria da Informação (Shannon, 1948; Borst e Theunissen, 1999) é uma especialização da teoria matemática da probabilidade aplicada ao estudo da transmissão de informação em sistemas de comunicação e constitui atualmente um método bastante rigoroso de quantificar a informação que transita em um sistema nervoso apenas observando os padrões elétricos em longas séries de dados. Em nosso caso, uma das grandes vantagens, é que na Teoria da Informação não é necessário fazer nenhuma afirmação a priori sobre a relevância ou sobre o significado dos padrões observados, nem mesmo sobre a natureza do código neural (Chacron, 2006).

O rigor da Teoria da Informação vem de medir a precisão da transferência de informação, determinando a distribuição de probabilidades de resposta dado um particular sinal de entrada, ou estímulo. Assim, podemos saber exatamente quanto do estímulo está, de alguma maneira, presente na resposta. Em redes neurais, a Teoria da Informação pode ser usada para quantificar precisamente a confiabilidade das funções de estímulo-resposta e sua utilidade tem sido reconhecida desde o início de seu desenvolvimento (Borst e Theunissen, 1999).

Circuitos nervosos envolvidos em processamento sensorial podem ser considerados como paradigmas para a aplicação da Teoria da Informação, uma vez que o significado dos sinais elétricos é conhecido, pelo menos de maneira aproximada, no 
nível sensorial. Assim, a aplicação da Teoria da Informação ao estudo do comportamento de peixes elétricos estimulados por sinais complexos, que iniciamos com este trabalho, tem um grande potencial de trazer progressos para a compreensão das estratégias e dos padrões utilizados para a eletrocomunicação e suas aplicações em outras áreas. 


\section{2 - O sistema de eletro-localização/comunicação do peixe Gymnotus carapo}

Os peixes da espécie Gymnotus carapo foram escolhidos para este trabalho por serem facilmente encontrados em várias regiões do estado de São Paulo e por produzirem seus pulsos elétricos a uma taxa relativamente baixa $(\sim 50 \mathrm{~Hz})$, o que facilita o desenvolvimento do aparato para a aquisição de dados e a interface entre o peixe e computador que pretendíamos estabelecer.

O Gymnotus carapo, como todos os peixes elétricos de água doce do Novo Mundo, pertence a subordem Gymnotodei da ordem Cypriniformes. Aparentemente, todos os membros da subordem são elétricos (produzem impulsos elétricos). Os gimnotóides são delgados e alongados, não possuem nadadeira dorsal mas tem uma nadadeira anal muito longa, lembrando a lâmina de uma faca pontuda, daí muitas vezes serem popularmente chamados de "peixes-faca". Um exemplar típico de Gymnotus carapo é mostrado na figura 1 . É um peixe que produz pulsos a frequência média de $\sim 50 \mathrm{~Hz}$ com amplitude de $\sim 1 \mathrm{~V}$ a $2 \mathrm{~V}$ (Caputi, 1999), por isso são muitas vezes chamados de peixes elétricos de "campo fraco", e pode atingir mais de $45 \mathrm{~cm}$ de comprimento. Alimenta-se de invertebrados e também de peixes de vários centímetros de comprimento, inclusive da própria espécie (Bullock et al., 2006).

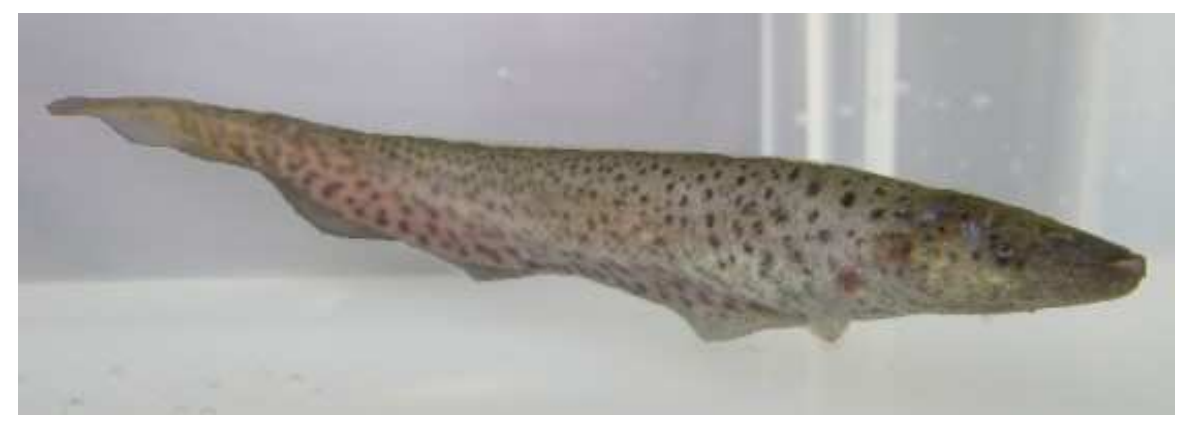

Figura 1 - Peixe elétrico de "campo fraco" Gymnotus carapo.

O comportamento elétrico de G. carapo tem atraído a atenção de pesquisadores a muito tempo (Bennett e Grundfest, 1959; Santana et al., 2001). A descarga elétrica é produzida por um agregado de tecidos especializados, que constituem o órgão elétrico. O comportamento eletromagnético do OE (Baffa e Corrêa, 1992) que em algumas espécies pode descarregar a mais de $1800 \mathrm{~Hz}$ tem sido um intenso objeto de estudo. Em Gymnotus, o OE é formado por células musculares especializados conhecidos como eletrócitos. Os eletrócitos estão, geralmente, entre as maiores células do animal e podem ser em forma de fita, disco ou fuso (Bullock et al., 2006). Freqüentemente estão dispostos em pilhas, com todas as células orientadas no mesmo sentido. Esta disposição é bastante comum e parece ser um resultado de evolução convergente para permitir uma produção máxima de voltagem pelo órgão (no caso dos peixes elétricos "fortes" como a enguia elétrica). Na figura 2 estão representados o orgão elétrico de G. carapo e uma série temporal típica de uma medida de seu sinal elétrico. 

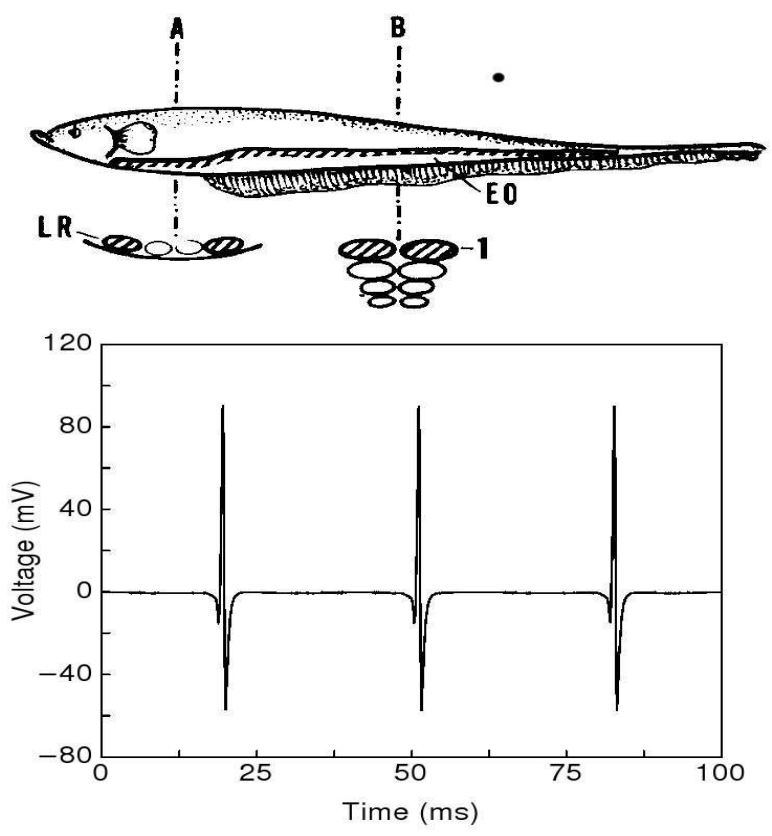

Figura 2 - Superior: o órgão elétrico (EO) de Gymnotus carapo possui duas partes. A parte anterior ou abdominal (corte A) é composta por duas colunas de eletrócitos arranjadas bilateralmente (LR). A parte caudal (corte B) é composta por quatro colunas de eletrócitos. Eletrócitos duplamente inervados (hachurados no desenho) ocorrem em LR (anterior) e na coluna 1 (caudal). Adaptada de Trujillo-Cenóz et al., 1984. Inferior: série temporal com descargas elétricas (DOEs) de G. carapo medidas na água com o eletrodo positivo colocado próximo a cabeça do peixe e o eletrodo negativo próximo da cauda - 0 pulso produzido é trifásico. Adaptada de Capurro e Malta, 2004.

Gymnotus carapo é um pulsador e, como tal, possui uma considerável amplitude para variar a taxa de descarga. Quando o animal está ativo, alimentando-se, é perturbado, ou de outro modo excitado, ele podem aumentar a taxa de descarga em várias centenas por cento. Uma razão possível para o aumento dessa taxa associada ao estímulo, é que o peixe utiliza seu orgão elétrico para interrogar seu ambiente mais freqüentemente de forma a obter a informação necessária à sobrevivência e muitas vezes é chamada de novelty response, em inglês (Caputi et al., 2003).

A descarga do órgão elétrico é comandada pelo sistema nervoso central. Medidas interpoladas do campo elétrico produzido pelo OE na região em torno do peixe é mostrado na figura 3 .

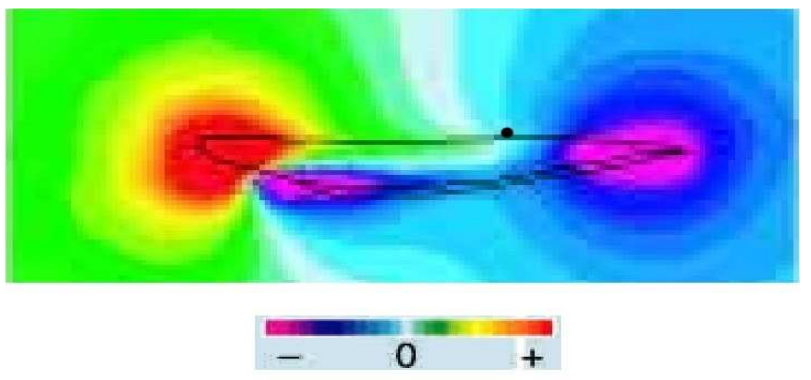


Figura 3 - Mapa do campo elétrico produzido na água nas proximidades de um Gymnotus carapo (visto lateralmente: esquerda - anterior, direita - caudal) em um instante no meio um disparo. A morfologia do orgão elétrico faz com que apareçam três pontos de intensidade máxima do campo no corpo do peixe. Cada um destes pontos apresenta uma evolução temporal do campo elétrico diferente, produzindo o sinal trifásico mostrado na figura 2. Adaptada de Assad et al., 1999.

O que permite aos peixes elétricos fracos utilizarem o campo elétrico pulsado produzido pelos seus próprios OE para localizar objetos em sua vizinhança e para se comunicar é a presença de uma enorme quantidade de sensores de campo elétrico (eletroreceptores) espalhados pelo corpo do peixe (Castelló et al., 2000). Em Gymnotus carapo existe uma região em torno da mandíbula que apresenta a maior concentração de eletroreceptores em todo o corpo do peixe, conforme mostrado na figura 4. A grande concentração de receptores (100 receptores $/ \mathrm{mm}^{2}$ em peixes de $10 \mathrm{~cm}$ de comprimento) em uma pequena região e outras semelhanças das imagens elétricas com o sistema visual humano levou a chamar esta região em torno da mandíbula do peixe de "fóvea elétrica". Só que ao invés de depender de uma fonte externa, como a luz do sol, o mecanismo de produção de imagens elétricas a partir de um sinal auto-produzido é semelhante à ecolocalização utilizada pelos morcegos e recebe o nome de eletrolocalização.
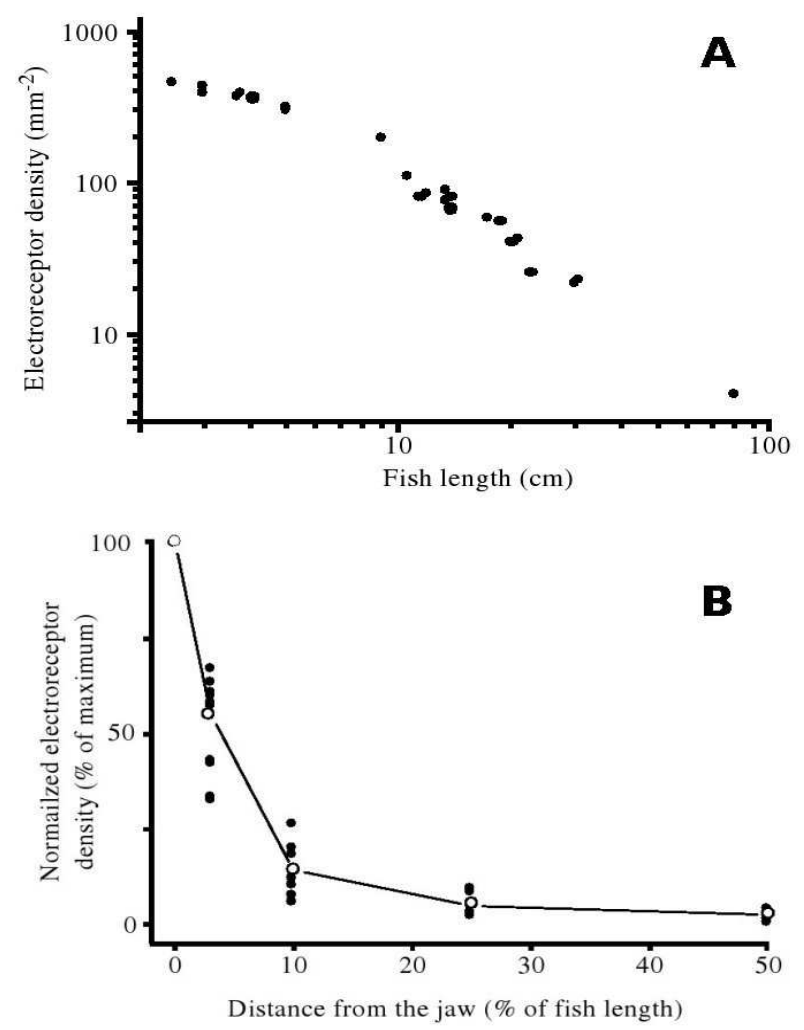

Figura 4 - Distribuição de eletroreceptores no corpo de Gymnotus carapo. A Densidade de eletroreceptores na região da "fóvea elétrica" (ao redor da mandíbula) em funcão do comprimento do peixe. B - Distribuição relativa de eletroreceptores em funcao da distância à fóvea. Extraída de Castelló et al., 2000. 
A eletrolocalização, extremamente útil para permitir a locomoção em águas turvas ou à noite, pode ocorrer de modo passivo ou ativo. No modo passivo, o peixe percebe a presença de outro peixe elétrico sentindo o campo elétrico produzido pelo "intruso". A eletrolocalização ativa baseia-se na distorção das linhas do campo elétrico produzido pelo próprio peixe pelos objetos ao redor: objetos próximos da superfície do corpo do animal intensificarão ou atenuarão o fluxo da corrente transcutânea local, conforme sua resistividade seja mais baixa ou mais alta do que a da água circundante conforme mostrado na figura 5. Estas mudanças locais nos padrões de fluxo representam a "imagem elétrica" dos objetos. A intensidade e o contraste de tais imagens são uma função da resistência relativa da pele e geometria do corpo. Por exemplo, um longo filamento caudal, como ocorre em G. carapo e também em muitas outras espécies de peixe elétrico, amplia a faixa de eletrolocalização do animal e o contraste das imagens elétricas é aumentado conforme o animal curve seu corpo e cauda ao redor dos objetos, intensificando o campo elétrico na região de interesse e a resolução. A eletrolocalização é tão importante que é mantida em funcionamento mesmo enquanto o peixe "dorme" (Stopa e Hoshino, 1999), provavelmente para evitar um ataque surpresa de algum predador.
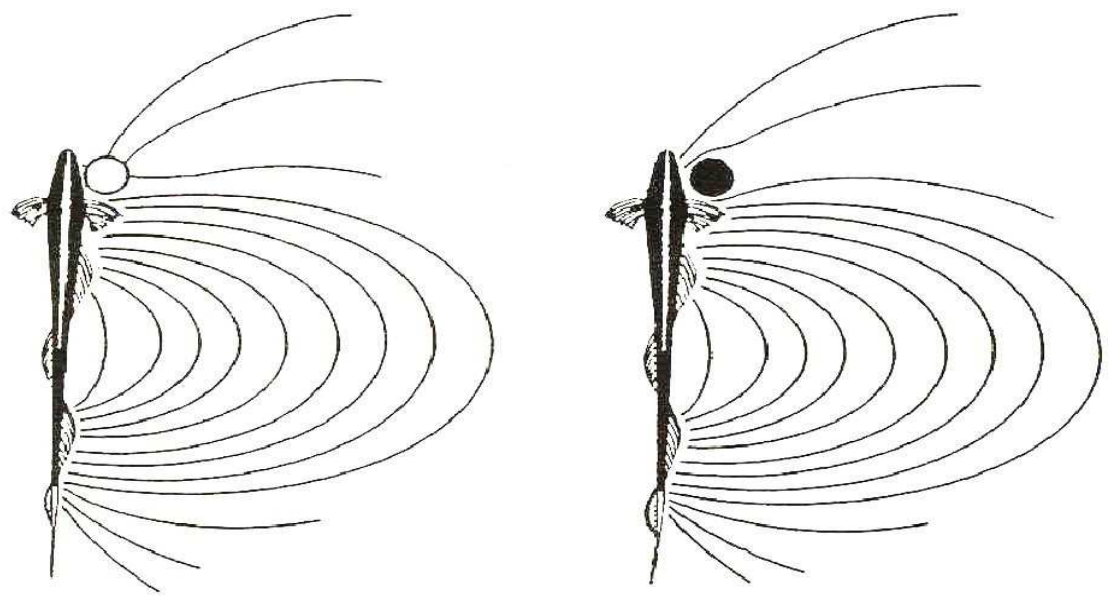

Figura 5 - Eletrolocalização em peixes elétricos fracos. O campo elétrico nas vizinhanças do animal é distorcido por objetos presentes no ambiente. Esquerda(direita): objeto com alta(baixa) condutividade elétrica. Extraída de DeCoursey, 1993.

As imagens elétricas são projeções bidimensionais do ambiente sobre a superfície do corpo do animal, o que pode ser então comparado com a retina no domínio da visão. Os eletroreceptores são organizados em padrões de campos receptivos, os quais assemelham-se aos campos receptivos visuais em termos de centros excitatórios, vizinhanças inibidoras, sensibilidade a movimentos unidirecionais etc. Parece que a visão e a eletrolocalização desenvolveram princípios semelhantes no processamento de imagens bidimensionais do ambiente (Bullock et al., 2006). 
As descargas do orgão elétrico também têm um importante papel na comunicação social. A identificação do sexo e da espécie freqüentemente baseia-se nas características das descargas típicas da espécie e do sexo e o estado comportamental de um animal freqüentemente se reflete nos modos particulares da atividade elétrica. Em Gymnotus carapo, um indivíduo dominante assinala suas ameaças e intenções de ataque por característicos aumentos na taxa dos DOEs e por breves interrupções. O indivíduo dominado assinala sua submissão por um período de interrupção, podendo silenciar seu orgão elétrico desde alguns segundos a minutos (Bullock et al., 2006).

Quando dois peixes elétricos de uma mesma espécie se aproximam pode ocorrer uma séria deterioração de sua capacidade de sensoriamento elétrico devido à interferência entre seus sinais elétricos. Para evitar essa interferência e permitir a concentração de vários peixes em uma mesma vizinhança cada peixe altera a frequência de seus pulsos para que eles não se sobreponham (Takizawa et al., 1999; Capurro e Malta, 2004; Tan et al., 2005). Este mecanismo, que ocorre automaticamente, é conhecido como "resposta para evitar interferência" (JAR - do inglês JammingAvoidance Response), e em vertebrados é provavelmente um dos comportamentos mais bem compreendidos em nível neural (Fortune et al., 2006).

Os peixes pulsadores sul-americanos como G. carapo respondem tipicamente à interferência causada pela DOE de um peixe vizinho com uma aceleração ou, menos freqüentemente, uma desaceleração na taxa de repetição dos pulsos. Podem manter uma taxa diferente e assim reduzir a chance de pulsos coincidentes. Apenas uma série de várias coincidências consecutivas é grave em termos de prejuízo na detecção de objetos, e basta manter os pulsos estranhos a poucos milissegundos da coincidência.

\section{3 - Metodologia}

\section{1 - Animais utilizados nos experimentos}

Os animais utilizados nesse trabalho foram adquiridos de coletores/pescadores que os comercializam na feira de Guarulhos, CECAP. No total foram utilizados 11 peixes da espécie Gymnotus carapo (popularmente conhecidos como "tuvira"), com tamanho entre $15 \mathrm{~cm}$ e $25 \mathrm{~cm}$, mantidos separadamente em aquários com oxigenação permanente e que são limpos e têm sua água trocada a cada 2 semanas. Os animais são alimentados 2 vezes por semana com um cardápio variado de alimento vivo, que consiste de pequenos peixes (lips), minhocas, artêmias, tenébrios ou insetos.

\section{2 -Teoria da Informação e cálculo da informação mútua média entre dois sinais}

A Teoria da Informação (Shannon, 1948; Borst e Theunissen, 1999, Rabinovich et al., 2002) segue uma abordagem estatística em que o conteúdo de um sinal é baseado em conceitos estatísticos como incerteza ou variabilidade. Na Teoria da Informação o significado de um sinal (ou evento) não é importante em si, mas sim a probabilidade $P(x)$ de que o determinado evento $x$ ocorra.

A informação associada a um evento é definida como sendo $\log _{2}(1 / P(x))$. É utilizado log na base 2 porque normalmente é usada a unidade arbitraria bits ( 0 ou 1$)$ e a função $\log$ porque é a única função matemática capaz de transformar multiplicação de probabilidades em somas de informação como é necessário para a teoria. 
Quando um evento tem uma baixa probabilidade de ocorrer, a informação sobre o evento é maior que a informação de um evento que possui maior probabilidade de ocorrer. Assumindo que tenhamos uma série de eventos $x$ pertencente ao conjunto $\left(\right.$ sinal $\left._{1}, \operatorname{sinal}_{2}, \ldots, \operatorname{sinal}_{n}\right)=X$. A entropia é definida como o valor médio da informação de todos os eventos, e é expressa por

$$
H(X)=-\sum_{x} P(x) \log _{2} P(x)
$$

$H(X)$ é grande se o sistema possuir muitos estados com a mesma probabilidade de ocorrência (alta variabilidade), por outro lado será nula se e somente se o sistema permanecer em um único estado. A entropia é assim sempre maior ou igual a zero.

Um neurônio ou rede neural fornece alguma informação sobre um estímulo se sua resposta $x$ for correlacionada de alguma maneira com mudanças no estímulo. Se o estímulo não mudar no decorrer do tempo (sinais periódicos = estímulos constantes) não há transmissão de informação porque a informação contida no estímulo é nula. A Informação Mútua é um método de determinar se a variabilidade da resposta é correlacionada com a variabilidade do estímulo. Para calcular a informação mútua é necessário comparar as diversas respostas devido à aplicação de diferentes estímulos. Cada estímulo precisa ser apresentado um número razoavelmente grande de vezes de modo a tornar a estatística relevante. A informação $i$ entre um estímulo s pertencente a $S$ (conjunto de todos os estímulos possíveis) e uma resposta $\mathrm{r}$ pertencente a $R$ (conjunto de todas as respostas possíveis) é definida como:

$$
i(s, r)=\log _{2}\left(\frac{p(s, r)}{p(s) p(r)}\right),
$$

onde $p(s, r)$ é a probabilidade conjunta de ocorrerem o estímulo $s$ e a resposta $r$. Se os processos forem estatisticamente independentes, $p(s, r)=p(s) p(r)$ e a informação mútua é nula. A Informação Mútua Média (IMM) é a média da informação contida em todos os possíveis eventos:

$$
\operatorname{IMM}(S, R)=\sum_{s, r} p(s, r) i(s, r),
$$

que também pode ser expressa por

$$
\operatorname{IMM}(S, R)=H(R)-H(R \mid S),
$$

onde $H(R \mid S)$ é a entropia condicional da resposta em função do estímulo. A Informação Mútua Média é sempre maior ou igual a zero. A IMM é simétrica, ou seja $\operatorname{IMM}(\mathrm{S}, \mathrm{R})=\operatorname{IMM}(\mathrm{R}, \mathrm{S})$, ela apenas mostra a informação que os sinais tem em comum sem indicar qual a direção em que a informação se propaga. 




Na figura 6 mostramos um exemplo de obtenção dos pares (s,r) a partir das séries temporais de DOEs $A(t)$ e $B(t)$, medidas simultaneamente em dois animais interagentes para o posterior cálculo da IMM.

Figura 6 - Exemplo de um pequeno trecho do comportamento de disparos de dois peixes elétricos e o esquema utilizado para codificar a posição das DOEs. SINAL A e SINAL B correspondem aos DOEs detectados nos dois animais, respectivamente. As séries de disparos dos dois animais $A(t), B(t)$ são divididas em um grande número de pequenos intervalos de igual duração $\Delta \mathrm{t}$ e um bit é atribuído a cada um desses intervalos. As séries de disparos são então transformadas em longas strings de bits 0 ou 1: se dentro de um intervalo ocorreu um disparo um bit 1 é atribuído àquela posição, caso contrário, um bit 0 é atribuído. Partindo do início das duas strings (posição $=0$ ) uma "palavra" de número arbitrário de bits (no exemplo $=8$ bits) é extraído do SINAL A (estímulo $=\mathrm{s}$ ) e o mesmo número de bits (resposta $=r$ ) é extraído do SINAL B pulando um intervalo de atraso (arbitrariamente escolhido para permitir uma relação de causalidade). Incrementando-se sucessivamente o contador posição obtém um grande conjunto de pares $(s, r)$ que é usado para calcular a IMM entre os sinais. $\Delta$ t e o número de bits usado em $s$ e $r$ devem ser escolhidos de modo a maximizar a entropia dos conjuntos $\{s\}$ e $\{r\}$.

Para verificar a significância estatística de nossos resultados do cálculo da IMM utilizamos o método dos surrogados (Theiler et al., 1992) conforme mostrado no apêndice A2.

\section{3 - Aquisição e análise de dados}

Durante nossos experimentos, séries temporais longas dos sinais dos DOEs de um ou dois peixes são digitalizadas (taxa de digitalização $=50 \mathrm{KHz}$ ), os instantes de disparo são detectados (com resolução de $0.1 \mathrm{~ms}$ ) e armazenados em disco, por um computador de aquisição de dados (Dasylab, Dasytech, Alemanha). No caso de sinais de dois peixes gravados simultâneamente, um programa em $\mathrm{C}++$ faz o cálculo da informação mútua média a partir dos arquivos armazenados conforme descrito a seguir (e exemplificado na figura 6).

A série temporal dos disparos é inicialmente dividida em um grande número de pequenos intervalos de igual duração $\Delta \mathrm{t}$ e é então transformada em uma longa string de bits 0 ou 1 (se dentro de um intervalo $\Delta$ t ocorreu um disparo, um bit 1 é atribuído àquela posição, caso contrário, um bit 0 é atribuído). Partindo do início das duas strings (posição $=0$ ) um determinado número de bits é extraído do SINAL A e atribuído ao 
elemento $s$ (posição) do conjunto $\{s\}$. Saltando um intervalo de atraso (arbitrariamente fixado para permitir uma relação de causalidade) o mesmo número de bits é extraído do SINAL B e atribuído ao elemento $r$ (posição) do conjunto $\{r\}$. Incrementando-se sucessivamente o contador posição obtém-se um grande conjunto de pares $(s, r)$ que é usado para calcular a IMM entre os sinais. $\Delta$ t e o número de bits usados em $s$ e $r$ são arbitrários e serão escolhidos de modo a maximizar a entropia dos conjuntos $\{s\} e\{r\}$.

A escolha do número de bits da palavra $(s, r)$ deve ser suficientemente grande para comportar palavras com o tamanho necessário para capturar toda a informação da mensagem. Em nosso caso, tentamos palavras com diversos números de bits e obtivemos resultados coerentes e semelhantes, conforme mostrado no apêndice A1.

Obtemos o valor da IMM entre os sinais usando todos os pares $(s, r)$ dentro de uma janela de 40 segundos que começa no início das séries. O início dessa janela é então deslocado de 20 segundos e novo cálculo de IMM é obtido e, assim, sucessivamente até o final das séries de dados. Dessa maneira, obtemos como varia a IMM a cada 20 segundos para este intervalo de atraso entre os sinais. Para verificarmos a importância do atraso (latência da resposta) para o valor da IMM, repetimos o cálculo para diversos atrasos entre $-5 \mathrm{~s}$ e $+5 \mathrm{~s}$. Os resultados são apresentados em gráficos em que plotamos o valor da IMM (em código de cores) em função do tempo do experimento e do parâmetro atraso entre os sinais.

A teoria da informação nada afirma sobre a direção do fluxo de informação, entretanto o parâmetro atraso que introduzimos permite associarmos os eventos em uma seqüência causal em que a direção de propagação da informação emerge naturalmente. 


\section{4 - Desenvolvimento do aparato experimental}

\section{1 - Aparato inicial}

O aparato inicial consistia em um aquário com 8 eletrodos (figura 7). Cada eletrodo foi construído com um fio de aço inóx atravessando a camada de silicone da vedação do aquário, fazendo um contato elétrico entre a água e um fio blindado externo. Cada um dos oito eletrodos foi colocado no vértice de um paralelepípedo de água dentro do qual o peixe pode se mover livremente. Eletrodos diagonalmente opostos foram ligados uns aos outros no fundo e em cima do aquário de maneira a simplificar a detecção. O sinal obtido com esta associação de eletrodos foi amplificado diferencialmente $($ ganho $=100)$ e digitalizado por uma interface analógico-digital (ADC) National PCI MIO 16-E1 a uma taxa de $\sim 50 \mathrm{kHz}$. Um programa de aquisição de dados em linguagem gráfica (DasyLab, Dasytech, Alemanha) foi desenvolvido para detectar os instantes dos DOEs do peixe e gravá-los em disco para posterior análise.

Este aparato inicial apresentou algumas limitações como a ocorrência de alguns disparos que não eram detectados, principalmente quando o peixe adotava certas conformações (por exemplo dobrado em forma de U). Além disso a baixa impedância entre eletrodos diagonais atraía a atenção do peixe que ficava muito tempo tentando atacá-los até acostumar-se. Com apenas um sinal final da configuração de eletrodos não era possível inferir de nenhuma maneira a posição do peixe no aquário exclusivamente desse sinal elétrico. Como os peixes são muito sensíveis à vibrações mecânicas, as medidas só podiam ser feitas quando não haviam pessoas circulando no prédio do laboratório, e decidimos reformular o aparato.

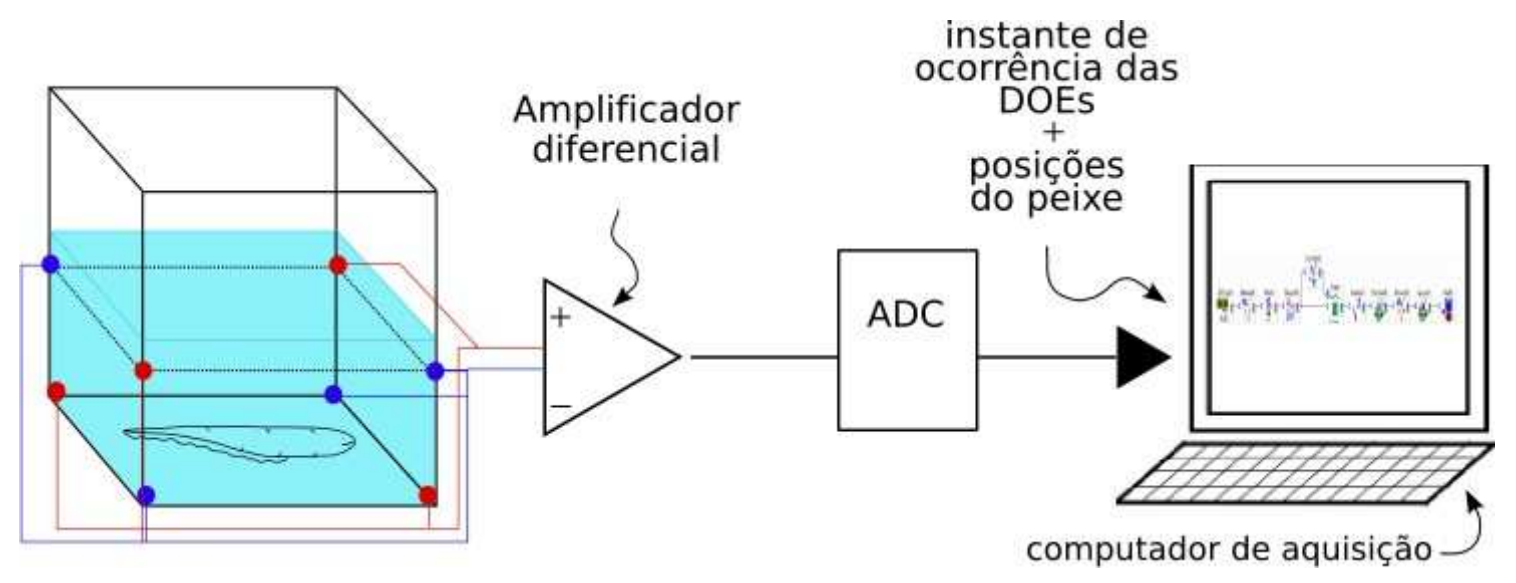

Figura 7 - Aparato experimental inicial: 4 dipolos interligados detectam os pulsos elétricos do peixe. O sinal passa por um amplificador diferencial e é digitalizado em uma placa conversora ADC num microcomputador, onde um programa de aquisição em linguagem gráfica detecta os instantes de ocorrência dos pulsos e armazena para posterior análise. 


\section{2 - Aparato final}

O novo aparato consiste de 2 aquários de vidro de $(40$ x 40 x 44) $\mathrm{cm}$ dispostos verticalmente em uma estrutura de madeira (figura 8a). Cada aquário fica dentro de uma caixa de $45 \mathrm{~cm}$ construída com compensado (virola) de $20 \mathrm{~mm}$ de espessura, revestida internamente de chapas de alumínio de $0,3 \mathrm{~mm}$ formando uma blindagem eletromagnética (gaiola de Faraday). Estas caixas que contém os aquários, por sua vez, foram suspensas por cabos de aço a uma caixa externa mais larga $(69 \mathrm{~cm})$, também construída com compensado (virola) de $20 \mathrm{~mm}$ de espessura e revestida internamente de chapas de alumínio de 0,3mm formando uma segunda gaiola de Faraday. Entre a caixa externa e as internas há 2 camadas de espuma acústica de $3 \mathrm{~cm}$ com um intervalo de $4 \mathrm{~cm}$ entre elas. A espuma serve para isolar o peixe de possíveis ruídos sonoros no ambiente e o espaço entre as espumas serve para impedir a propagação de ondas mecânicas (vibração) da caixa externa para as internas.

Essa caixa externa foi suspensa por cabos de aço presos à vigas no teto do laboratório. Os cabos de aço estão presos à pedaços de barra roscada parafusadas nas paredes da caixa de compensado (figura 8b). Esta foi a melhor maneira que encontramos para isolar os aquários das vibrações do prédio do laboratório e permitir medições das DOEs em dias normais, quando há pessoas trabalhando no laboratório e circulando pelo prédio. 


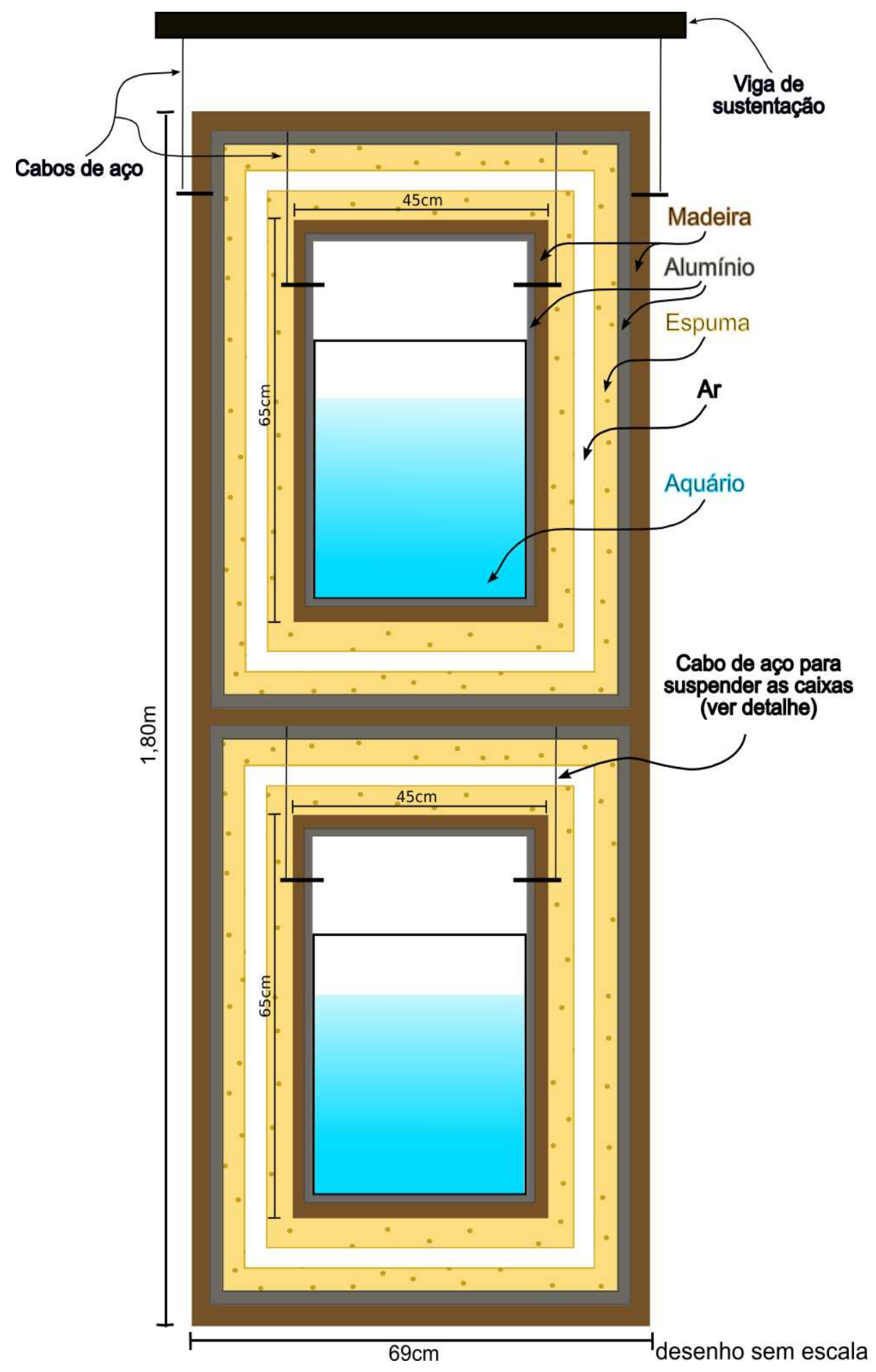

Figura 8 a - Aparato experimental: os aquários estão dentro de caixas de compensado de madeira, revestido de lâminas de alumínio que promovem isolamento eletromagnético (gaiola de Faraday). Essas caixas foram suspensas por cabos de aço dentro de uma caixa maior. Duas camadas de espuma de $3 \mathrm{~cm}$ cada com um intervalo de $4 \mathrm{~cm}$ entre elas foram utilizadas para isolamento acústico e mecânico. A caixa maior foi também suspensa por cabos de aço fixados a uma viga no teto do laboratório, reduzindo a passagem de vibrações do prédio que podem interferir em nossa tomada de dados. 


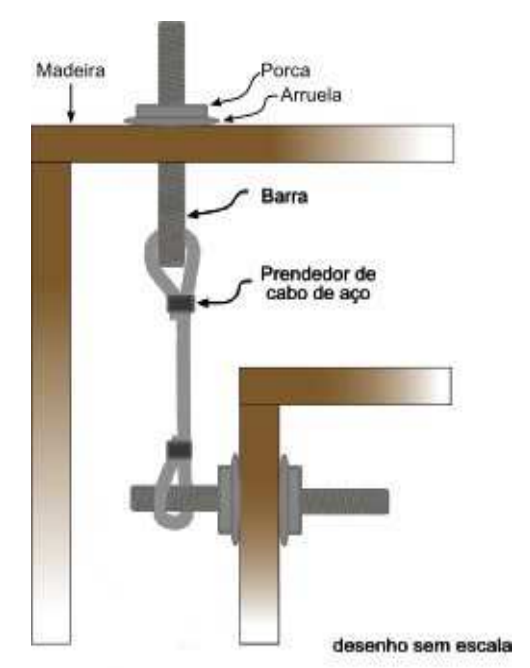

Figura 8 b - Detalhe de como as caixas foram suspensas por cabos de aço através de pedaços de barra roscada presos no compensado de madeira.

A ligação dos eletrodos foi alterada de modo a permitir estimar a posição do peixe dentro do aquário. Novamente 8 eletrodos de aço inóx (para não haver oxidação em contato com a água) foram introduzidos pela parede de silicone vedante: 4 na base do aquário sendo um em cada vértice e mais 4 eletrodos colocados a $40 \mathrm{~cm}$ acima destes, ou seja, a poucos milímetros da superfície da água (o aquário é preenchido com água até que esta adquira um formato aproximadamente cúbico). Um dos eletrodos da base foi escolhido como referência, e o sinal dos outros 7 eletrodos é amplificado diferencialmente (ganho 100 ) em relação á referência, formando assim, 7 dipolos sensores. Quanto mais perto de um dos eletrodos o peixe estiver, maior a amplitude do sinal medida por ele.

Como o sinal do peixe tem uma fase negativa e outra positiva com amplitude diferente, é possível medir estas amplitudes e determinar se é a cabeça ou a cauda que está mais próxima do eletrodo. Além disso, comparando as amplitudes relativas entre os diversos dipolos podemos determinar nas proximidades de qual eletrodo o peixe se encontra: o aquário foi dividido em 8 sub-volumes iguais (figura 9), em um dos vértices de cada volume há um eletrodo, então o eletrodo com maior amplitude positiva (em relação à referência), por exemplo, indica que a cabeça está no respectivo volume. De maneira similar ao que era feito no primeiro aparato, um computador com o software Dasylab (Dasytech, Alemanha) foi usado para medir os sinais dos diversos dipolos e detectar os instantes dos pulsos dos peixes nos dois aquários.

Devido à agressividade e territorialismo do Gymnotus carapo, evitamos colocar dois peixes soltos em um mesmo aquário para não machucá-los. Além disso, se colocarmos 2 peixes em um mesmo aquário teremos uma grande dificuldade para separar os sinais dos peixes, sobretudo devido ao movimento destes. Assim, para estudar o comportamento do peixe na presença de sinais de outros peixes, criamos um "peixe artificial", que é um dipolo móvel, de $15 \mathrm{~cm}$ de comprimento, montado dentro de um segmento de tubo de PVC para imitar a geometria do órgão elétrico de um peixe médio. 
Este dipolo é estimulado pela saída de um conversor digital-analógico controlado por um segundo computador dedicado à detecção em tempo real e produção de estímulo, onde um programa de controle, escrito em linguagem $\mathrm{C}$, produz os padrões de estímulo em tempo real. Em grande parte dos experimentos realizados na literatura, nos quais os peixes eram estimulados, eram usadas ondas senoidais ou quadradas por somente alguns segundos e a reação do peixe era analisada nos poucos segundos que se sucediam aos estímulos.

O sinal de estímulo consiste de um padrão de disparos que simula os disparos de um peixe verdadeiro: cada disparo corresponde a um pulso obtido de um peixe real (foi feita um média de vários pulsos sobrepostos de um dos peixes) que é produzido com amplitudes constantes (como se o peixe estimulador estivesse parado dentro do tubo de PVC). Também é possível alterar o formato do pulso, podendo simular peixes com alguma lesão, na qual alguma componente do sinal foi modificada, ou mesmo formato de ondas de peixes de espécies diferentes.

O intervalo entre os disparos é controlado em tempo real pelo programa: podemos escolher entre padrões periódicos, padrões aleatórios, séries de intervalos obtidos previamente de algum peixe e, numa versão mais recente do programa, os pulsos de um peixe são detectados em tempo real em um dos aquários e a cada pulso um estímulo de amplitude constante é produzido no outro aquário e vice-versa (figura 10), assim, podemos estudar o comportamento dos dois peixes se comunicando em tempo real enquanto estão livres para se movimentar em seus aquários.

Como o peixe falso está sempre na mesma posição, podemos medir sua contribuição para o sinal de cada eletrodo, e subtraí-la a posteriori, separando o sinal de estímulo do sinal de resposta do peixe.

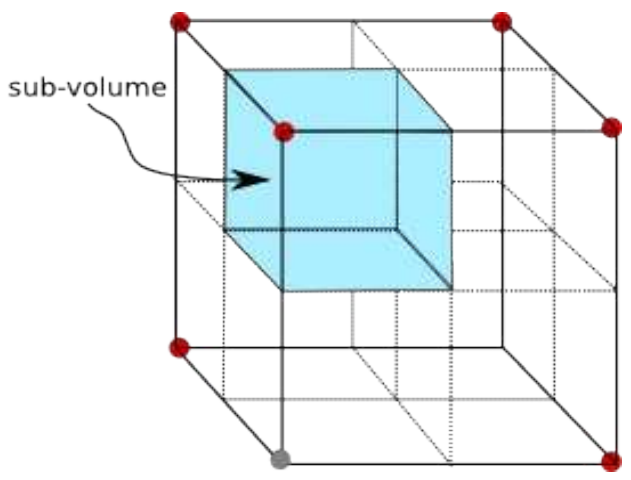

Figura 9 - Aquário divido em 8 subvolumes, comparando as amplitudes relativas entre os diversos dipolos podemos determinar nas proximidades de qual eletrodo o peixe se encontra. 


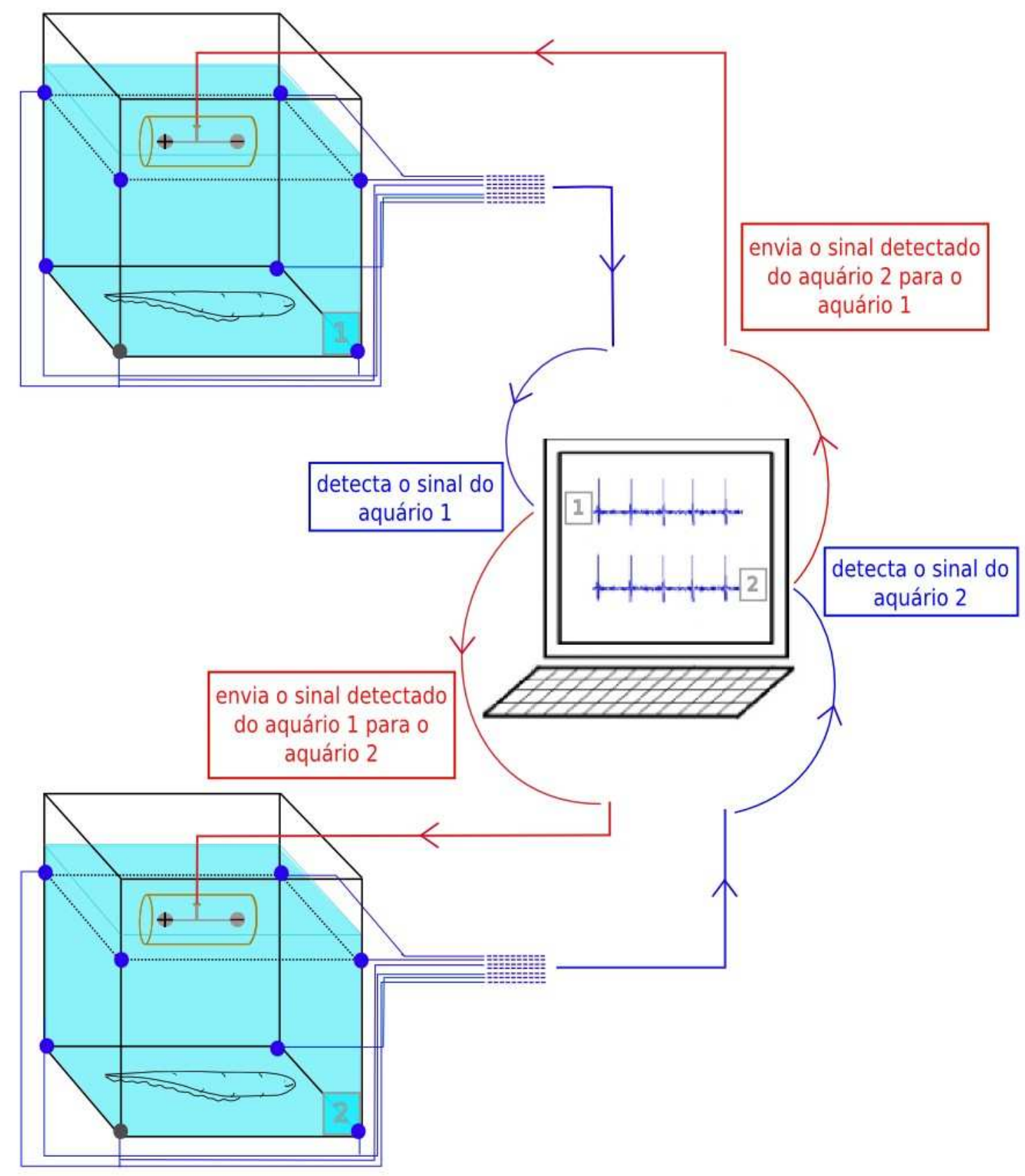

Figura 10 - Aparato para conectar dois peixes: os pulsos de um peixe são detectados em tempo real em um dos aquários e a cada pulso um estímulo de amplitude constante é produzido no outro aquário e vice-versa por um peixe falso (dipolo móvel, de $15 \mathrm{~cm}$ de comprimento, montado dentro de um segmento de tubo de PVC para imitar a geometria do órgão elétrico de um peixe médio). Como o dipolo está sempre na mesma posição, podemos medir sua contribuição para o sinal de cada eletrodo, e subtraí-la a posteriori, separando o sinal de estímulo do sinal de resposta do peixe. 


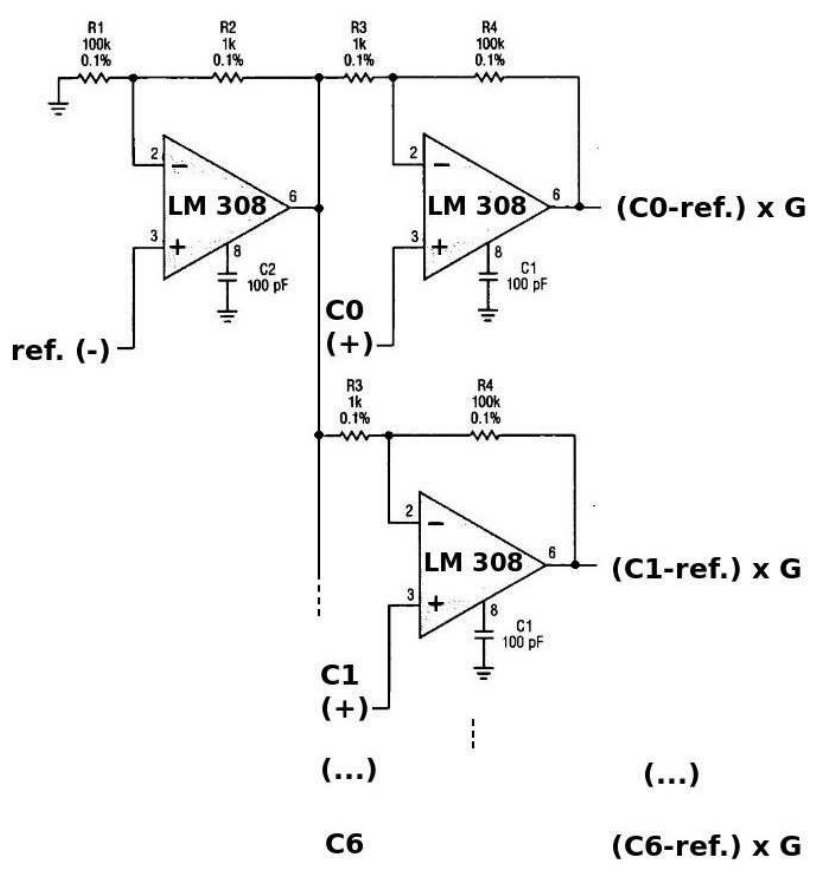

Figura 11 - Circuito elétrico simplificado dos amplificadores diferenciais montados para detectar os disparos do peixe elétrico. Há eletrodos em cada um dos vértices do cubo de água dentro do aquário. Um dos eletrodos (ref.(-)) é usado como referência para todos os outros 7 eletrodos $(C 1(+) \ldots C 7(+))$. Apenas duas das sete saídas são mostradas nessa figura. $O$ ganho do circuito para todos os canais $(G \sim 100)$ é dado por: $G=1+(R 1 / R 2)$, desde que $\mathrm{R} 4=\mathrm{R} 1$ e R3=R2 em cada um dos amplificadores. Adaptada de Linear Technology Datasheet, 2000.

Com um arranjo de 8 eletrodos distribuídos nos vértices do cubo de água formado dentro do tanque de medidas obtemos o sinal dos disparos do peixe para qualquer posição deste dentro do tanque. A amplificação do sinal de disparo do peixe é feita de modo diferencial - usamos um dos eletrodos como referência e amplificamos o sinal de cada um dos outro 7 eletrodos em relação ao de referência. $\mathrm{O}$ circuito baseia-se no amplificador operacional de baixo ruído para instrumentação LM 308 (Linear Technology Datasheet, 2000). O ganho do circuito pode ser ajustado alterando-se os valores dos resistores R1 a R4 em todos os amplificadores. Em nossas medidas um ganho $\mathrm{G}=100$ foi adequado para produzir sinais máximos com amplitude entre $-8 \mathrm{~V}$ e $+8 \mathrm{~V}$, suficientemente grandes para facilitar a análise de dados e abaixo da amplitude máxima de entrada dos conversores ADC (entre -10V e +10V))(figura 11).

Os experimentos que envolvem a conexão de dois peixes foram viabilizados com a construção de um equipamento que processa os sinais dos dois tanques parte através de eletrônica analógica, parte através de software em tempo real. A conexão entre o hardware analógico e o programa em tempo real é feita através de uma placa interface Digidata 1200B (Axon Inc.) que possui dois conversores digital analógicos (DACs) e 16 conversores analógico-digitais (ADCs), dos quais apenas dois são usados para melhorar a velocidade do programa. O diagrama em blocos parcial dos circuitos eletrônicos e do programa de aquisição/controle em tempo real do experimento é mostrado na figura 12.

Quando o programa detecta que o peixe do tanque 1 disparou, um estímulo para o tanque 0 é produzido (através do DAC 0). Este estímulo é aplicado ao dipolo dentro do tanque 0 e depois de um atraso de alguns microssegundos (tempo de propagação do 
sinal na água desde o dipolo até os sensores) este sinal aparece nos eletrodos somado ao sinal dos pulsos do peixe verdadeiro. Esse sinal composto, medido nos 7 eletrodos, é amplificado diferencialmente, elevado ao quadrado, somado e invertido analogicamente. O computador lê esse sinal processado através do ADC 0 e o soma com o sinal de estímulo gerado previamente elevado ao quadrado e atrasado para que os impulsos do estímulo apareçam exatamente no mesmo instante nos dois sinais mas com amplitudes contrárias. Somando-se os sinais é possível eliminar a interferência do estímulo e recuperar apenas os pulsos do peixe verdadeiro, mesmo quando ocorre uma sobreposição destes com os do estímulo. Os instantes de disparo do peixe verdadeiro são detectados através de um comparador de nível e são usados para produzir os pulsos de estímulo para o tanque 1. O mesmo algoritmo é aplicado aos sinais do tanque 1 que geram os impulsos para o peixe do tanque 0 .

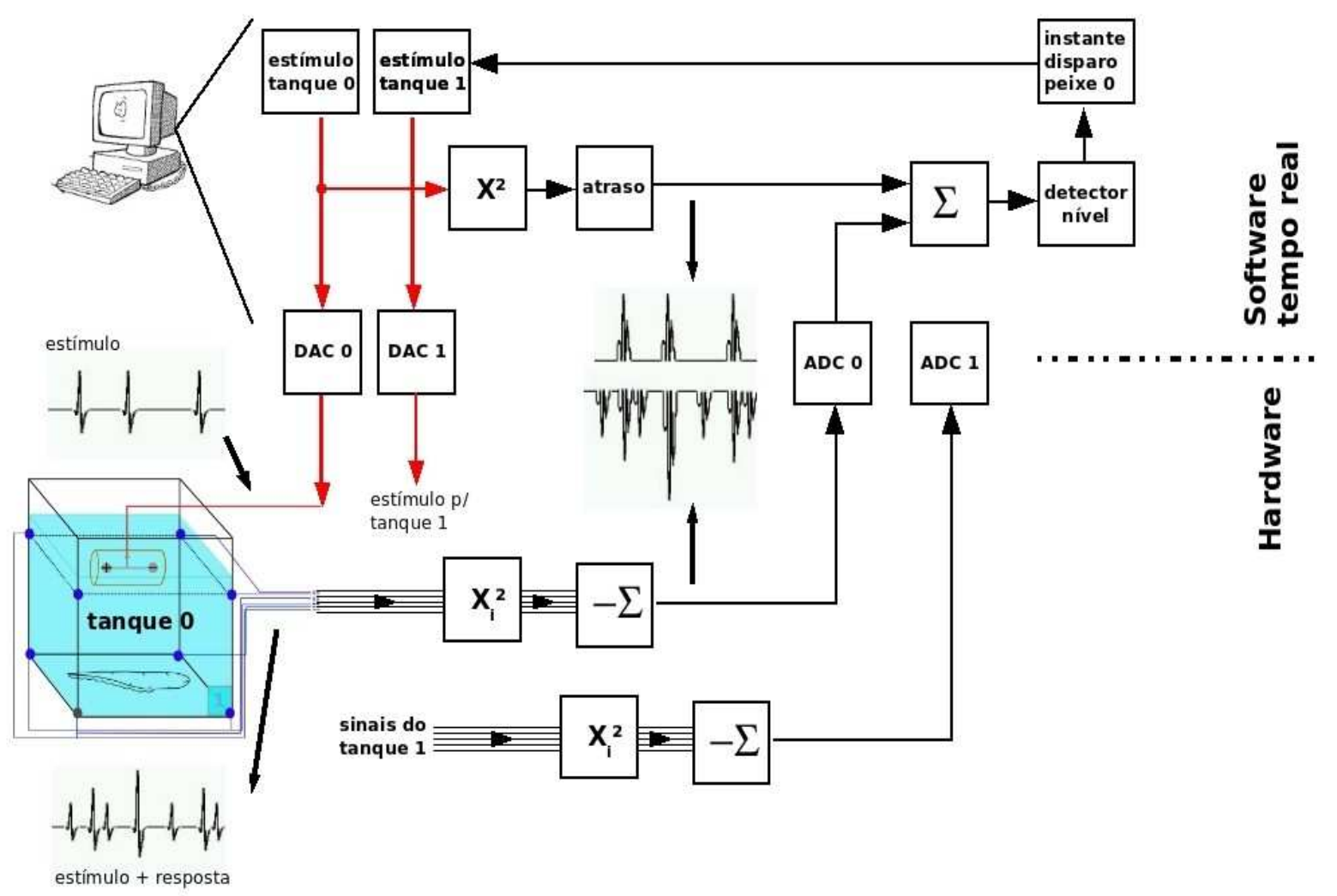

Figura 12 - Diagrama em blocos parcial da circuitaria analógica e do programa de aquisição em tempo real para a conexão de dois peixes. O estímulo artificial para o tanque 0 é produzido por computador (DAC 0) e aparece misturado com os pulsos do peixe real nos diversos eletrodos. Um circuito analógico eleva os sinais ao quadrado, soma os sinais dos diversos canais e aplica este sinal obtido a uma das entradas de uma placa ADC do computador. O programa em tempo real é capaz de eliminar os impulsos devido ao estímulo gerado subtraindo deste sinal o correspondente ao estímulo artificial atrasado. Os pulsos do peixe verdadeiro são detectados por simples comparação com um nível pré-determinado e usados para estimular o tanque onde está o peixe 1. O mesmo ocorre para os estímulos introduzidos no tanque 1. 


\section{5 - Experimentos e análise de dados}

\section{1 - Experimentos}

A medida das descargas do órgão elétrico (DOEs) é sempre feita de maneira não invasiva: o(s) peixe(s) é(são) colocado(s) em aquário(s) com uma matriz cúbica de 8 eletrodos conforme descrito anteriormente para os dois aparatos utilizados e foram realizadas séries de medidas com o(s) peixe(s) nas seguintes condições:

(1) Medida longa (4 dias) sem estímulo com aparato inicial, medida de $24 \mathrm{~h}$ sem estímulo externo aparato novo;

(2) Medidas com estímulos externos intercalados em épocas de 30 minutos cada com a seguinte sequiência: ausência de estímulo, série de intervalos de DOEs de outro peixe, ausência de estímulo, série de DOEs com intervalos aleatórios entre (15 e 20)ms, ausência de estímulos.

(3) Dois peixes interagindo em tempo real.

\section{2 - Medidas longas dos disparos de peixes na ausência de estímulos}

\section{-Medida longa (4 dias) sem estímulo externo com aparato inicial}

A partir da série de instantes de ocorrência dos DOEs detectados durante 4 dias (10.015.716 DOEs) utilizamos o software livre Octave (ambiente Linux) para calcular os intervalos entre os disparos do órgão elétrico (ISIs) e fazer histogramas separados com os valores dos ISIs para os dias e as noites, como mostrado na figura 13. Além disso também construímos um histograma no tempo (em inglês sliding window histogram) calculando histogramas para uma janela com 1000 ISIs, deslocando esta janela em 500 ISIs e assim, sucessivamente até o final da série, conforme mostramos na figura 14.

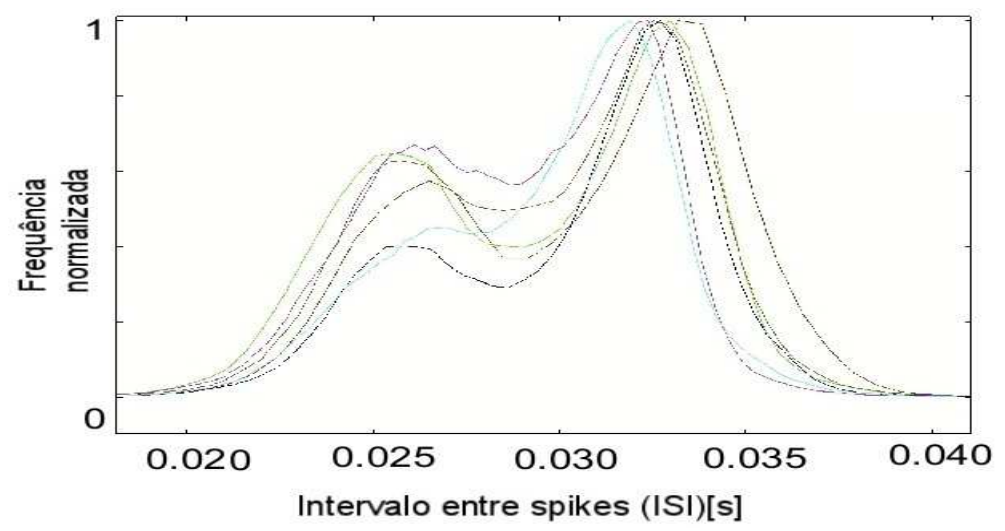

Figura 13 - Histograma normalizado do intervalo entre pulsos. Cada curva corresponde aos 4 dias e noites nas quais as DOEs foram medidas. 
No histograma total dos quatro dias de dados há 2 picos, um menor em $26 \mathrm{~ms}$ $(\sim 38 \mathrm{~Hz})$ e outro maior em $33 \mathrm{~ms}(\sim 30 \mathrm{~Hz})$. Cada uma das curvas coloridas corresponde a um dia ou noite em que as DOEs do peixe foram medidas. Observa-se que o peixe descarrega seu órgão elétrico preferencialmente em 2 valores de ISI, tanto de dia quanto de noite. Há apenas um pequeno deslocamento do máximo dos picos que pode ser explicado pela lenta mudança de temperatura do laboratório (durante os 4 dias que durou o experimento) que pode interferir na frequência das DOEs (Bullock et al., 2005)

No sliding window histogram podemos acompanhar como muda o comportamento dinâmico dos disparos no tempo, conforme mostrado na figura 14. A primeira faixa, da esquerda para a direita, corresponde à primeira noite e ao primeiro dia, a segunda faixa à segunda noite e ao segundo dia e assim por diante, até a quarta noite.

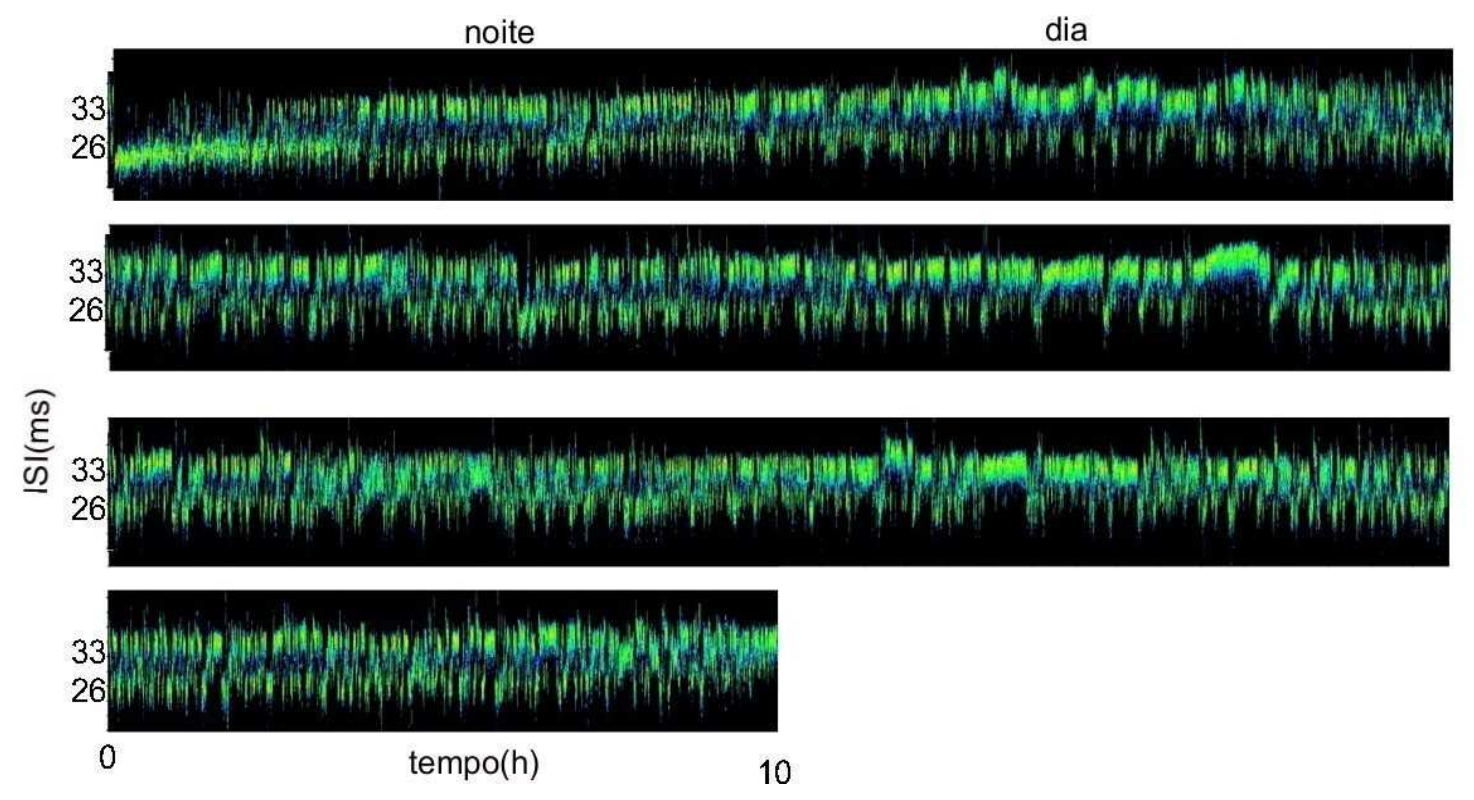

Figura 14 - Sliding window histogram (histograma no tempo) dos intervalos entre disparos (ISIs) dos quatros dias e noites. A primeira faixa, da esquerda para a direita, corresponde à primeira noite e em seguida o primeiro dia, a segunda faixa corresponde à segunda noite e ao segundo dia, e assim por diante até a quarta noite. Foram utilizados 1000 ISIs para cada histograma e o deslocamento entre histogramas é de 500 ISIs. Obs: azul = baixa probabilidade, verde $=$ alta probabilidade.

No começo da primeira faixa (próximo do instante em que o peixe foi colocado no aquário) nota-se a predominância de ISIs de $26 \mathrm{~ms}$ durante aproximadamente 2 horas. Neste período, o peixe estava extremamente estressado, nadando rapidamente e explorando todo o aquário com especial interesse pelos eletrodos. Logo após, aparece o pico de $33 \mathrm{~ms}$ e o animal passa a alternar rapidamente entre ISIs de $26 \mathrm{~ms}$ e $33 \mathrm{~ms}$. No primeiro dia (lado direito da primeira faixa) os ISIs continuam se alternando mas o peixe passa mais tempo pulsando em menor frequência (ISI $=33 \mathrm{~ms}, \sim 30 \mathrm{~Hz}$ ), no segundo dia isto se torna mais evidente, pois em um trecho no meio da série o peixe pulsa em baixa frequência por quase 1 hora. Esse comportamento se repete para os demais dias e noites.

Como o Gymnotus carapo possui hábitos noturnos, podemos associar às frequências altas um comportamento ativo e investigativo (enquanto ele não se 
acostumou com o aquário manteve os pulsos com a frequência média de $38 \mathrm{~Hz}$ ). Às frequências médias mais lentas, com ISIs de $\sim 33 \mathrm{~ms}$, podemos associar um comportamento relaxado onde, possivelmente, o peixe está parado em algum lugar do aquário. Entretanto, para sabermos realmente se esta relação é verdadeira, era preciso registrar o comportamento do animal no aquário (se ele se encontra parado ou movimentando-se, etc) e associá-lo com a frequência em que o OE está disparando. Estas questões motivaram o desenvolvimento do novo aparato experimental

\section{-Medida longa 24h sem estímulo externo com aparato final}

A partir da série dos tempos das DOEs detectados durante 1 dia com o aparato final calculamos intervalos entre os disparos do órgão elétrico (ISIs) e fizemos um sliding window histogram (histograma no tempo) com janela de 5 minutos e deslocamento de 5 minutos. A parte da esquerda corresponde à noite e a da direita, corresponde ao dia, figura 15.

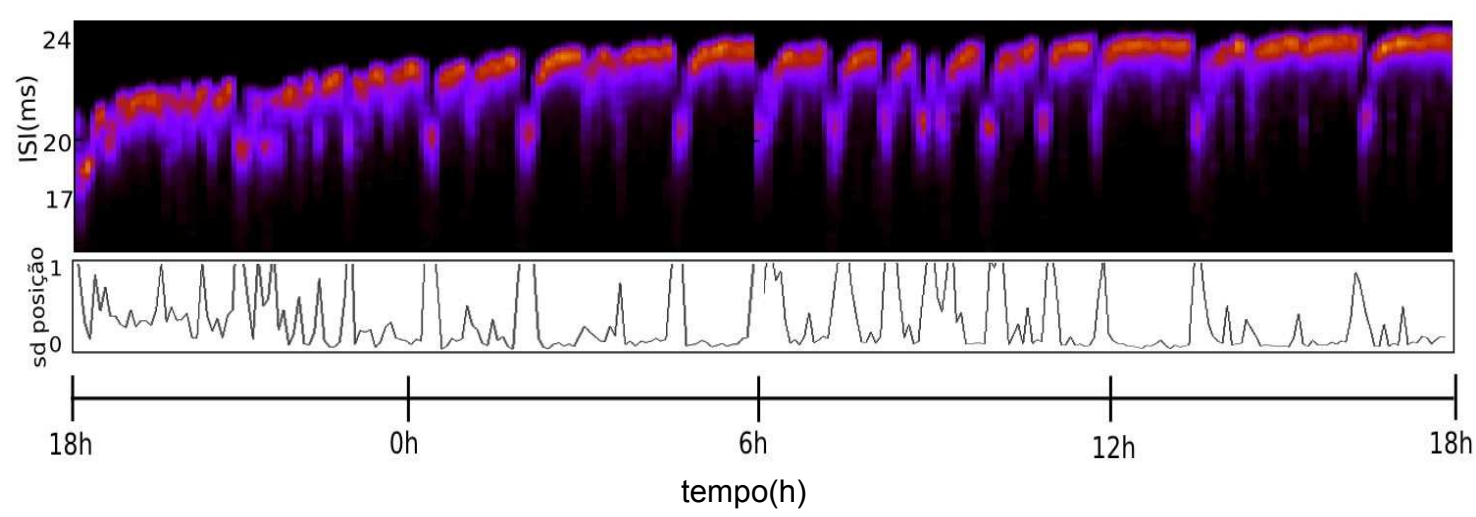

Figura 15 - Histograma no tempo de DOEs detectadas durante 1 dia (acima) e desvio padrão da posição de peixe (em baixo). Obs: azul = baixa probabilidade, amarelo = alta probabilidade.

No começo da primeira faixa (próximo do instante em que o peixe foi colocado no aquário), nota-se a predominância de ISIs de $17 \mathrm{~ms}$ durante aproximadamente 30minutos, neste período, o peixe costuma ficar estressado, nadando por todo o aquário. Logo após, aparece o pico de $22 \mathrm{~ms}$ o animal passa a alternar entre ISIs de $18 \mathrm{~ms}$ e 22 ms. À medida que amanhece, os ISIs de $22 \mathrm{~ms}$ predominam, e o comportamento de alternância de freqüências diminui, ou seja, o peixe passa mais tempo pulsando em apenas uma frequiência. Esse comportamento também foi visto no peixe medido com o aparato inicial, no qual foi feita uma medida longa de 4 dias, como mostramos anteriormente.

Para obter informações sobre o movimento do peixe durante o experimento calculamos o desvio padrão das amplitudes nos diversos eletrodos e somando estes sinais podemos inferir se o peixe está se movimentando muito (desvio padrão total grande) ou pouco (desvio padrão total pequeno ou nulo). Para compatibilidade com o sliding window hystogram usamos janelas de 5 minutos de duração com deslocamento 
de 5 minutos, seguindo assim até o final da série, obtendo o gráfico mostrado na figura 15( inferior). Nota-se que durante a noite o desvio padrão da posição é maior que durante o dia, indicando que nesse período o peixe está mais ativo.

Como o Gymnotus carapo possui hábitos noturnos, já esperávamos que ele se movimentasse mais nesse período. Ele percorre todo o aquário de maneira aleatória, não havendo uma rota preferencial.

A variação dos intervalos dos DOEs, quando o peixe está solto e sem qualquer estímulo externo, é dependente de sua movimentação, pelos gráficos acima nota-se que o peixe pulsa mais rápido, com ISIs indo de $\sim 22 \mathrm{~ms}$ para $\sim 18 \mathrm{~ms}$ (com predominância desses últimos) quando ele se movimenta.

Uma possível interpretação para essa relação entre movimento e aumento da taxa de disparo pode ser o fato do movimento do próprio peixe, ao levá-lo para uma nova região do aquário, evocar uma novelty response no sistema nervoso que tem que atualizar o mapa da região dos arredores.

\section{3 - Medidas com estímulos aleatórios e realistas produzidos por computador}

Escolhemos épocas de 30 minutos pois é o tempo médio que o peixe demora para que seus ISIs voltem a freqüência "normal" (mais relaxado) após ter sido colocado em um novo ambiente.

O mesmo experimento foi repetido com 6 peixes diferentes, recém adquiridos (ou seja, não adaptados ao ambiente do laboratório), medidos em horas distintas da manhã e da tarde e que apresentavam comportamentos distintos: alguns exemplares extremamente agressivos e outros bem acanhados e com tamanhos variando entre $15 \mathrm{~cm}$ e $25 \mathrm{~cm}$.

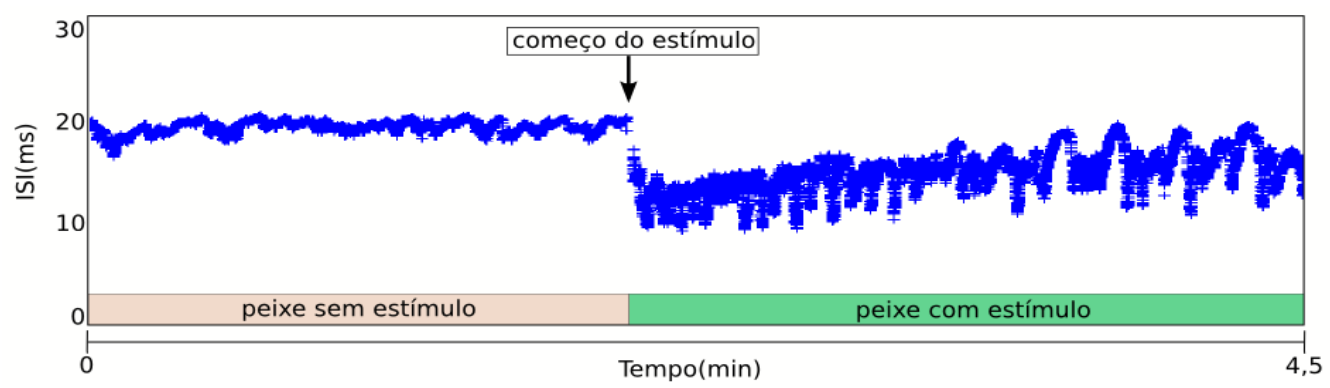

Figura 16 - Mudança na variabilidade dos ISIs devido ao estímulo apresentado.

Para analisarmos a variação nas freqüências dos disparos do órgão elétrico, fizemos o histograma no tempo usando janelas de 40 segundos com deslocamento de 20 segundos entre janelas. 

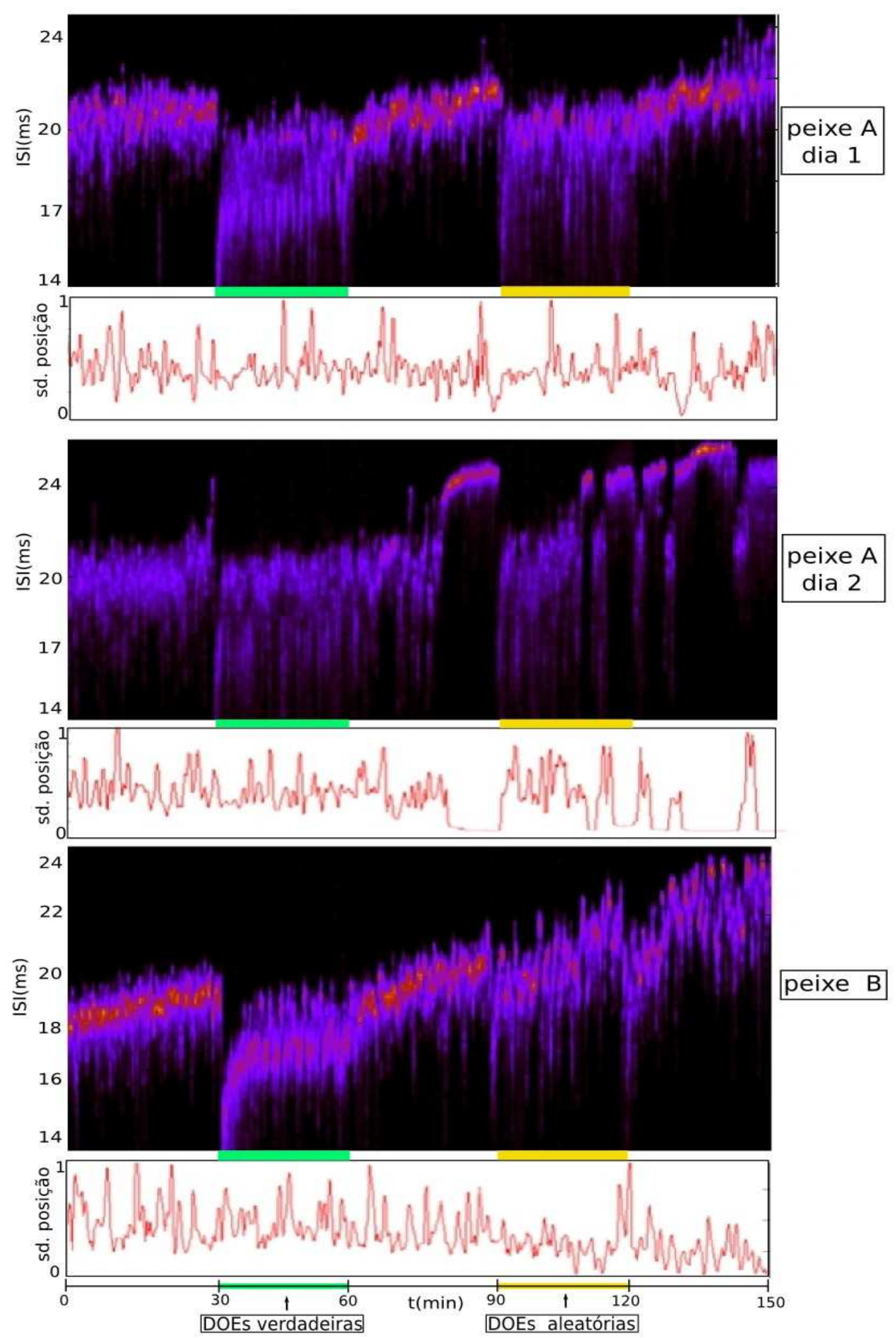

Figura 17 - Histograma no tempo e desvio padrão da posição. As faixas verdes correspondem às épocas de 30 min de estímulo com intervalos de DOEs de outro peixe e as faixas amarelas às épocas de $30 \mathrm{~min}$ de com DOEs com intervalos aleatórios de $(15$ a 20ms). Obs: azul = baixa probabilidade, amarelo = alta probabilidade. 
Ao começar parte do estímulo que contém ISIs de um peixe verdadeiro, a grande parte dos peixes silencia seu OE desde alguns segundos, para os mais agressivos, até minutos, para os mais medrosos. Logo após o silêncio inicial os peixes voltam a disparar com frequiência mais alta. Observamos que, após a volta ao regime de disparos, não apenas a frequência média aumenta, mas também a faixa de variação da frequência (o histograma torna-se mais borrado) (figuras 16 e 17). Neste experimento um dos animais apresentou freqüência bimodal nessa fase. Durante esse período todos os peixes se movimentaram por todo o aquário dando preferência para a região em que o peixe falso estava.

Depois de 30min (quando o estímulo foi interrompido), a frequência média dos peixes diminui imediatamente, assim como a faixa em que ela varia de disparo para disparo (nota-se que o histograma fica menos 'borrado'), nesse período a quantidade e a duração das pausas do $\mathrm{OE}$ é muito menor. A maioria dos peixes permaneceram se movimentando também.

Quando inicia a época de estímulo com ISIs aleatórios, também houveram pausas no OE de alguns segundos imediatas ao início do estímulo e durante toda a série, entretanto, a quantidade de vezes que isso ocorre é menor do que na época com ISIs verdadeiros. Novamente a freqüência diminui assim como sua amplitude de variação quando o estímulo é interrompido.

Alguns dias depois dos experimentos com os peixes novos, a mesma série de estímulos foi novamente apresentada para alguns peixes, figura 17. O histograma de ISIs no tempo mostra que as respostas de um mesmo peixe para os estímulos apresentados no primeiro dia diferem das do segundo. $O$ peixe que antes apresentou frequiência bimodal durante todo o período de estímulo de intervalos de DOEs de outro peixe, no segundo dia, apresentou esse comportamento para apenas alguns trechos da série.

$\mathrm{Na}$ ausência de estímulos, este animal ficou parado no aquário perpendicularmente ao peixe falso e sua frequiência diminuiu bastante indo de $50 \mathrm{hz}$ para $41 \mathrm{hz}$ (os ISIs mudaram de $20 \mathrm{~ms}$ para $24 \mathrm{~ms}$ ), até o começo da série de estímulo com intervalos de DOEs aleatórias. No final dessa série, ele parece ter se acostumado com os estímulos e relaxado, permanecendo imóvel por alguns minutos (paralelamente ao peixe falso) e com frequiência baixa $(41 \mathrm{~Hz})$, variando seus ISIs somente quando se movia (comportamento descrito na seção 5.2 quando o peixe estava sem estímulo).

Para associar quantitativamente as mudanças nos intervalos de disparos do OE com o estímulo apresentado aplicamos a Teoria da Informação. Para estudar como a IMM varia ao longo da série e para comparar com os histogramas feitos anteriormente, as séries de estímulo e de resposta foram divididas em janelas de 40 segundos ( 2500 bits), com deslocamento de 20 s entre janelas. Para verificar a relação de causalidade, os cálculos foram feitos usando atrasos de $-5 \mathrm{~s}$ a $5 \mathrm{~s}$. 

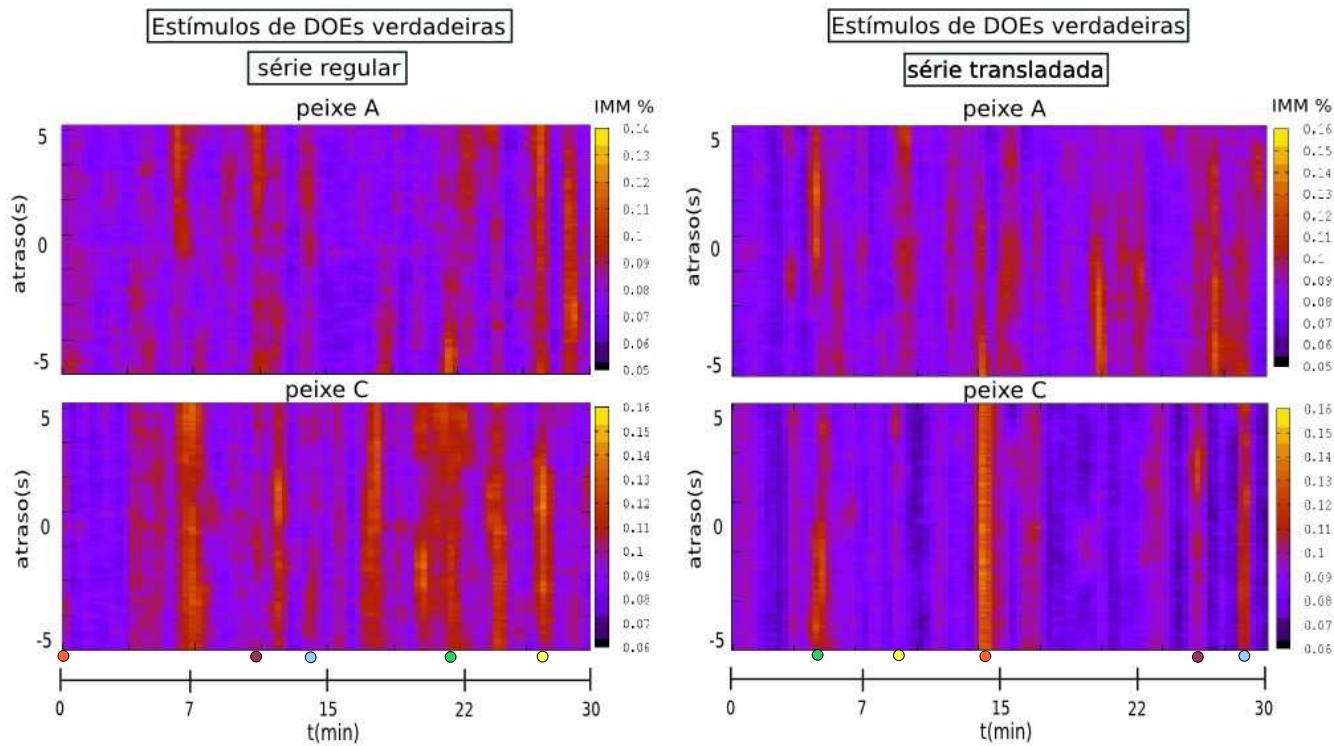

Figura 18 - IMM para a época de 30 min de estímulo com intervalos de DOEs de outro peixe para dois peixes diferentes. À esquerda : IMM para a série regular e à direita: IMM para quando a série de estímulos foi transladada a segunda metade da série se tornou o começo e o começo se tornou a metade final. Os círculos coloridos mostram os trechos que eram 'reconhecidos' na série de estímulos regular que continuaram a ser reconhecidos na série transladada.

A análise com teoria da informação revelou que diferentes peixes estimulados apresentaram padrões de disparos que corresponderam a picos de informação mútua média para os mesmos trechos da série de estímulos gravados de um peixe real (figura 18). Entretanto, comparando-se as séries dos intervalos entre pulsos dos DOEs do estímulo e dos vários peixes na mesma região, não foi observado nenhum padrão ou semelhança entre elas (figura 20-superior). Quando comparamos série de ISIs de um mesmo peixe tampouco há uma 'resposta padrão' para o mesmo estímulo apresentado em dias diferentes. No entanto, os pedaços das séries correspondentes aos picos de IMM sempre apresentam ISIs com grande variabilidade, sendo isso condição necessária mas não suficiente.

Os gráficos de IMM para o estímulo de DOEs de intervalos aleatórios não são tão semelhantes entre si quanto aqueles para o estímulo com intervalos de DOEs verdadeiras, não apresentando vários picos nas mesmas regiões para todos os peixes. $\mathrm{Na}$ figura 19, à esquerda, nota-se que quando o peixe estava parado, disparando o OE com baixa frequiência e com ISIs com pouca variabilidade, para essas regiões a IMM é muito baixa, indicando que não há transmissão de informação entre os sinais. O que confirma nossa hipótese que o peixe estava parado, relaxado e ignorando o sinal de estímulo. Nenhum dos peixes apresentou esse comportamento quando estavam sendo estimulados com intervalos de DOEs de outro peixe, em nenhum dos experimentos realizados. 

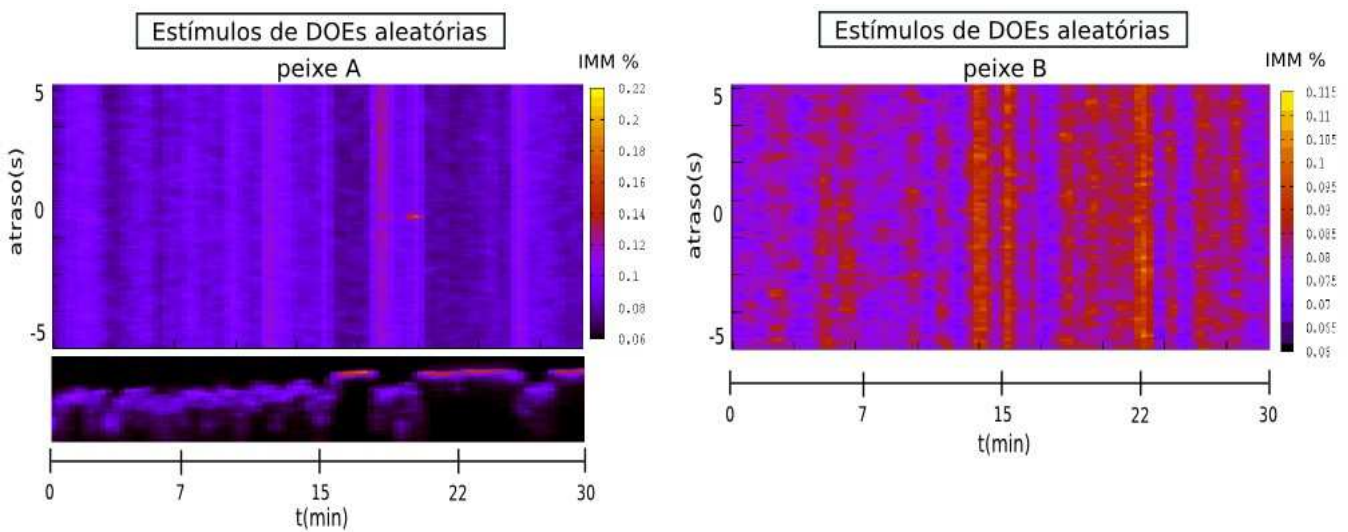

Figura 19 - IMM para quando foi apresentado estímulos com intervalos de DOEs aleatórias para dois peixes diferentes. À esquerda, em baixo, miniatura do histograma no tempo apresentado na figura 17 (peixe A dia 2).

\section{-Série de estímulos com intervalos de DOEs verdadeiras transladada}

Para testar se esses trechos seriam sempre 'reconhecidos', a série de estímulos foi divida ao meio e transladada, ou seja, a segunda metade da série se tornou o começo e o começo se tornou a metade final. Mesmo dessa maneira os picos da IMM continuaram ocorrendo nos trechos que correspondem aos trechos originais transladados (figura 18).

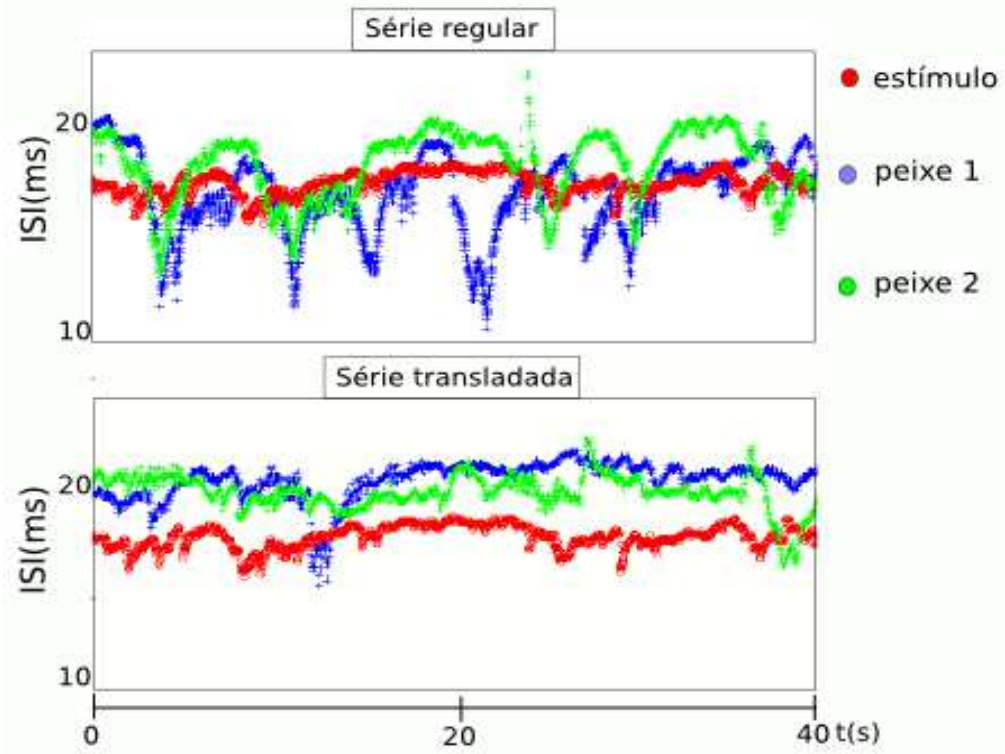

Figura 20 - Em cima: Pedaço da série de ISIs que corresponde a um pico de IMM para a série de estímulos regular. Em baixo: Mesmo pedaço da série de ISIs acima para a série transladada. Nota-se que o estímulo é o mesmo mas as respostas são diferentes e não apresentam um padrão facilmente identificável, apesar de haver pico de IMM para ambos experiementos. 
$\mathrm{Na}$ análise da série de ISIs do estímulo, tampouco foi encontrado um padrão facilmente reconhecível, apenas nota-se que esses trechos aprensentam grande variabilidade de ISIs se comparada com o restante da série(figura 20).

-Série de estímulos com intervalos de DOEs verdadeiras com um padrão de ataque introduzido

Realizamos outros experimentos onde introduzimos no padrão gravado de um peixe isolado explorando o aquário, 10 minutos do padrão de um peixe grande que agredia um peixe menor. Todos os peixes para os quais este estímulo foi apresentado 'reconheceram' os intervalos de agressão introduzidos, já que nossa análise apresentou picos na IMM exatamente nestas regiões (figura 22), no entanto no histograma de ISIs no tempo, no trecho correspondente a série de ataque, não se nota nenhuma característica que o faça diferente dos demais (figura 21).



Figura 21 - Histograma no tempo para dois peixes diferentes no qual foi introduzido um padrão de ataque (faixa verde) no meio da série de estímulos. Nesse trecho a série de ISIs não é diferente do restante, apesar da alta IMM nessa região. 


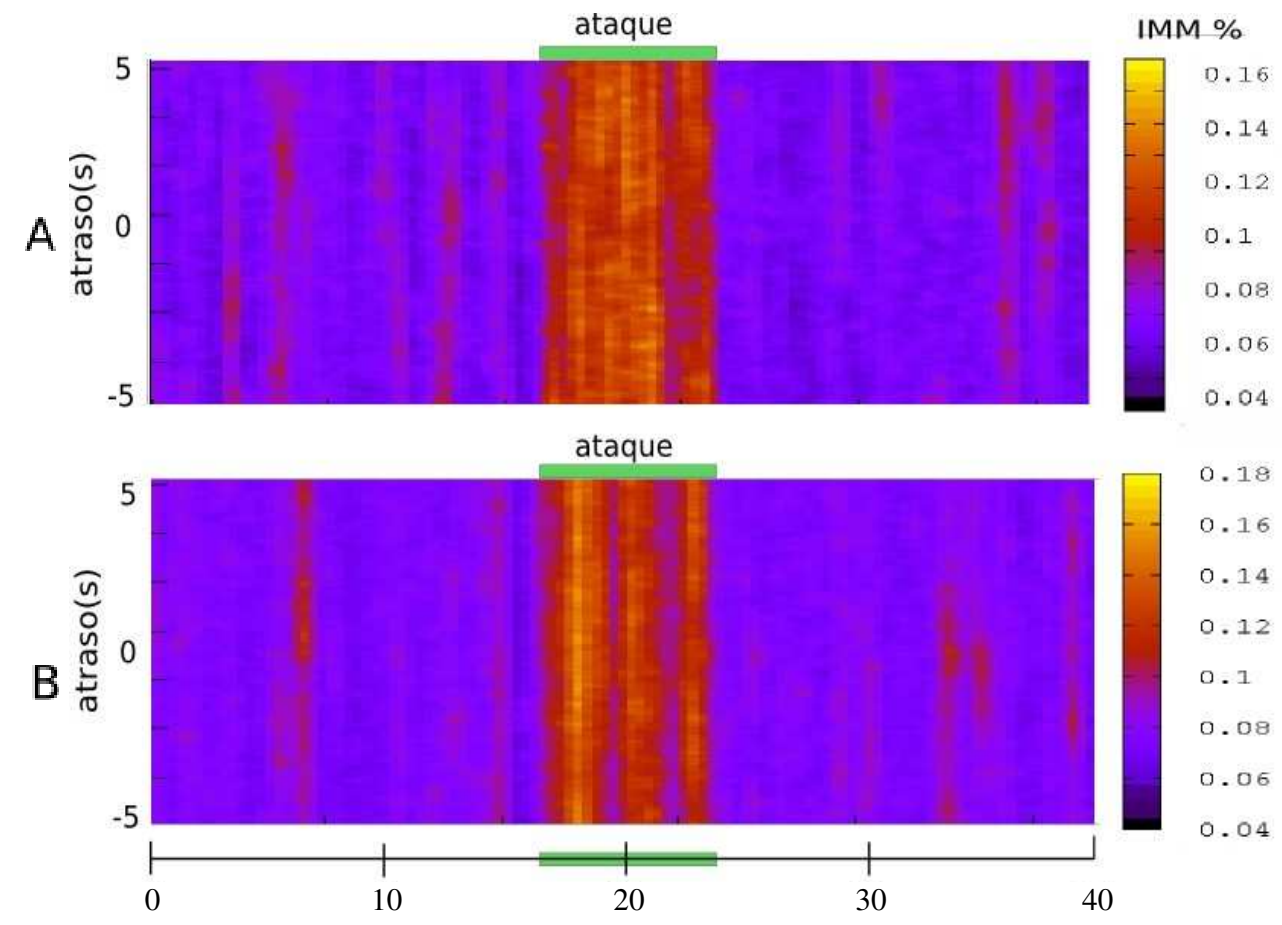

Figura 22 - IMM para a série de estímulos na qual foi introduzida um padrão de ataque (faixa verde). Há picos de IMM na região do ataque indicando que ambos os peixes 'reconheceram' o estímulo apresentado.

\section{-Série de estímulos com intervalos de DOEs de outro peixe}

Também foram feitas medidas usando como estímulo séries de outro peixe, mais agressivo do que o usado anteriormente, gravadas em duas situações diferentes: (a) nadando livre sem estímulo e (b) sendo estimulado. Pelos histogramas série dos ISIs de respostas não é possível identificar qual tipo de estímulo que estava sendo usado (figura 23). Como nos experimentos relatados anteriormente, também há trechos nas séries de estímulos que são reconhecidos por animais diferentes (picos de IMM na mesma região da série)(figura 24).

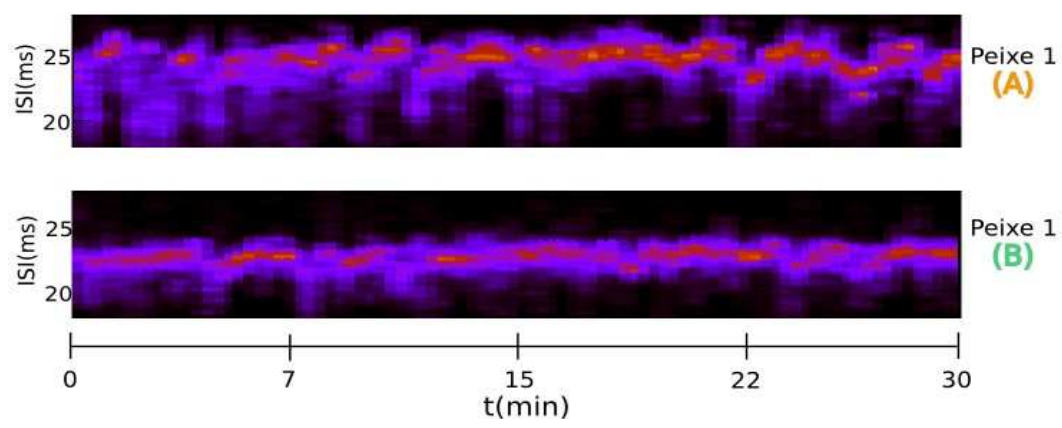

Figura 23 - Histograma no tempo para o mesmo peixe sendo estimulado por DOEs de outro peixe que havia sido medido em duas situações: $(A)$ sem estímulo e (B) sendo estimulado. 

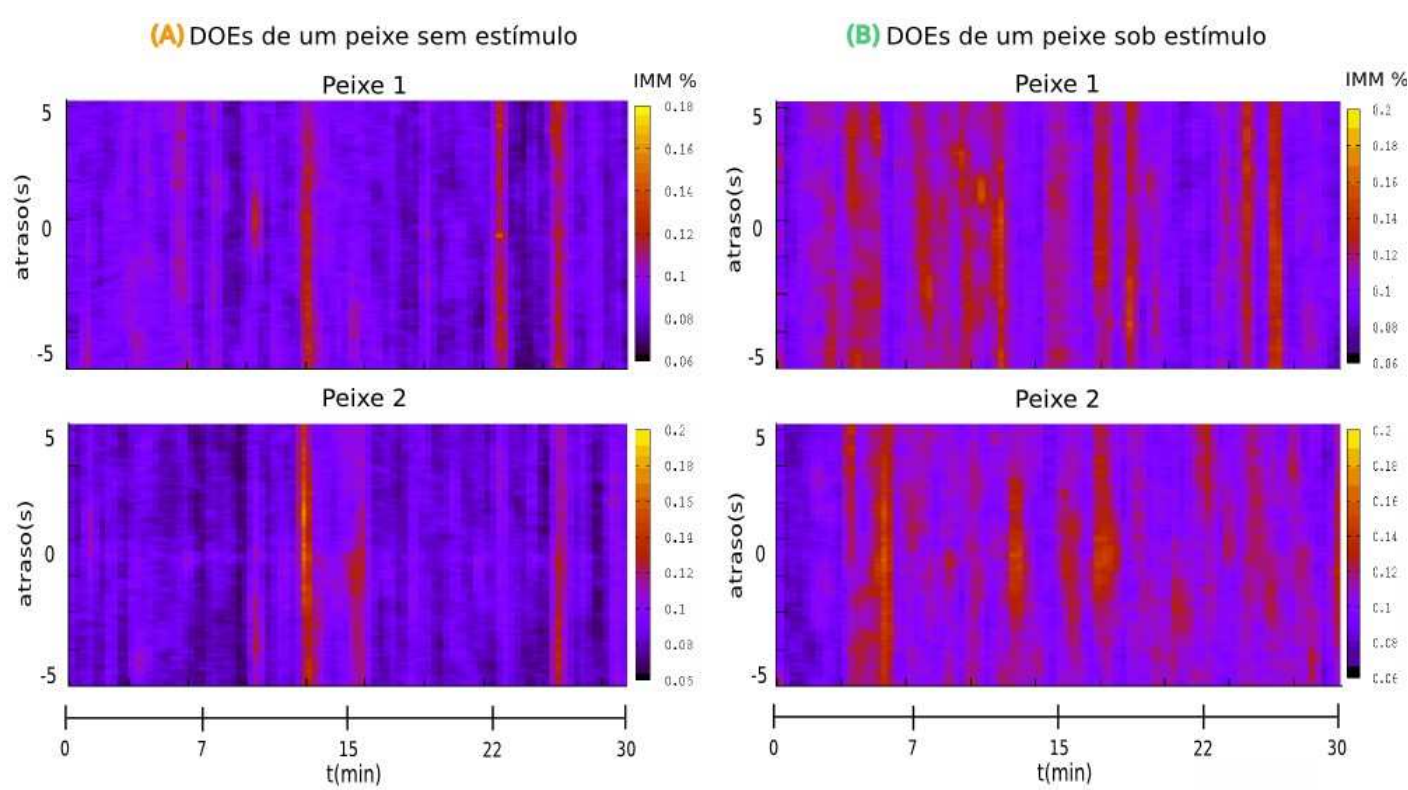

Figura 24 - IMM para dois peixes diferentes nos quais os estímulos usados provêm de DOEs de outro peixe que havia sido medido em duas situações: (A) sem estímulo e (B) sendo estimulado. Para as situações $(A)$ e $(B)$ há trechos das séries que são 'reconhecidos' por todos os animais para quais o estímulo foi apresentado.

Assim, concluímos que há algo no padrão do estímulo que é reconhecido pelos diferentes peixes e que provoca a resposta destes, mas que não pode ser trivialmente observado em nenhuma das séries de ISIs. Nossa hipótese é que estes picos devem corresponder a padrões complexos usados na comunicação entre os peixes.

\section{4 - Dois peixes interagindo remotamente por computador}

Dois peixes interagiram por 30 minutos através de dipolos estimulados por um computador onde um programa de controle foi desenvolvido para detectar os pulsos de um peixe e reproduzi-los no aquário do outro. Durante esse período os dois peixes se moveram por todo o aquário dando preferência para a região em que o peixe falso estava. Novamente, diversos picos de IMM são observados (figura 25b) sem haver nenhum padrão facilmente identificável na série de ISIs. A única característica é que nesses trechos os ISIs apresentam uma variabilidade grande, ao passo que numa região com baixa IMM, os ISIs se comportam de maneira bem mais regular (figura 25a e 25b). 


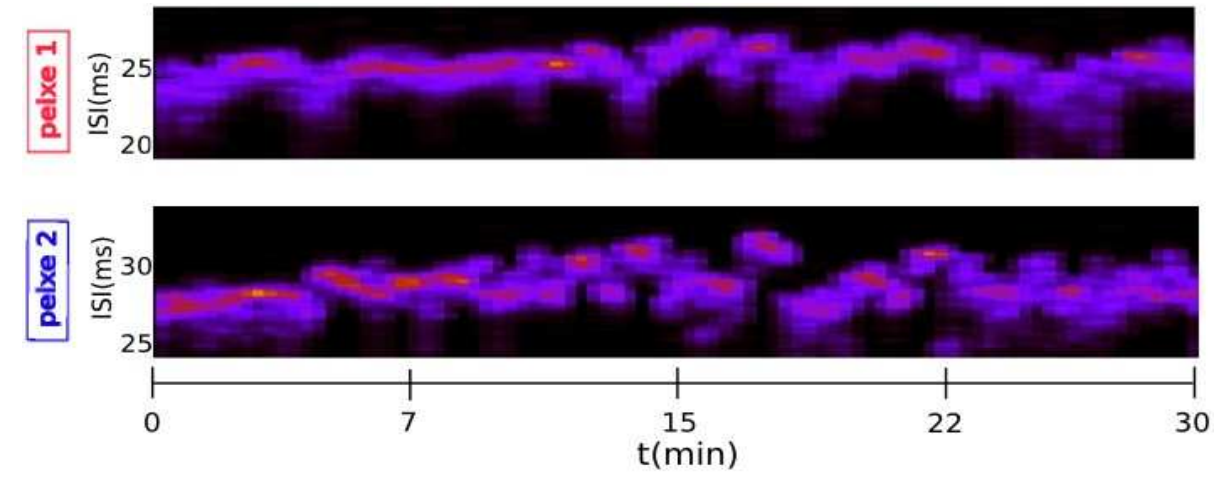

Figura 25 a - Histograma no tempo de dois peixes conectados

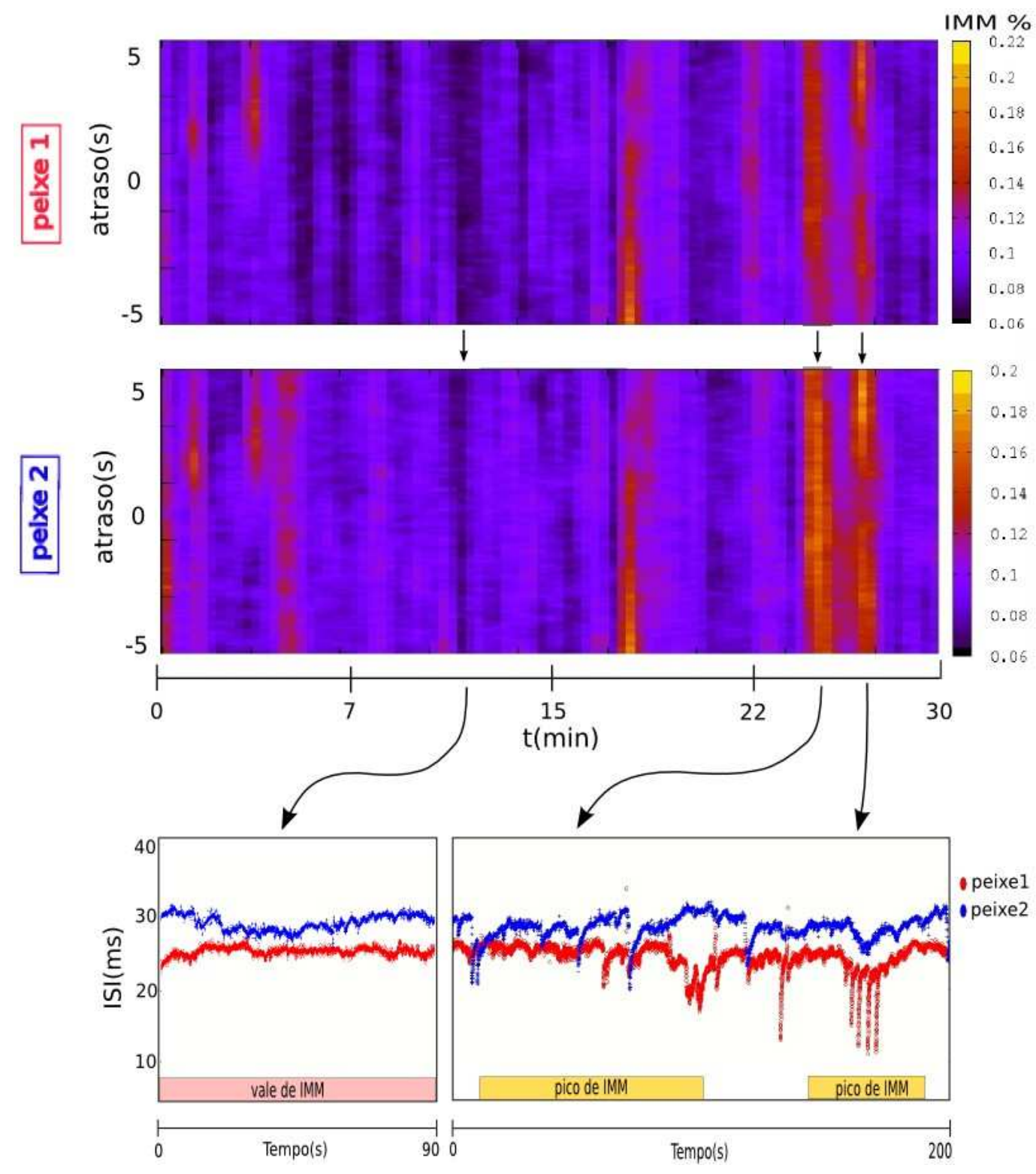

Figura 25 b - IMM para os dois peixes conectados e trechos da série de ISIs correspondentes a um vale de IMM (IMM baixa) e a picos de IMM. A variabilidade dos ISIs é maior para os trechos com IMM alta. 
Para verificar se os picos no gráfico da IMM não eram devido ao JAR (Capurro et al., 1998), no qual o peixe dominante altera sua freqüência evitando coincidências entre os pulsos, somamos em uma das séries valores aleatórios entre -2 e $2 \mathrm{~ms}$. Como os os efeitos do mecanismo do JAR são menores que a amplitude aleatória somada, eles não podem influir nos resultados observados com o cálcula da IMM. O resultado é mostrado nas figuras a seguir:

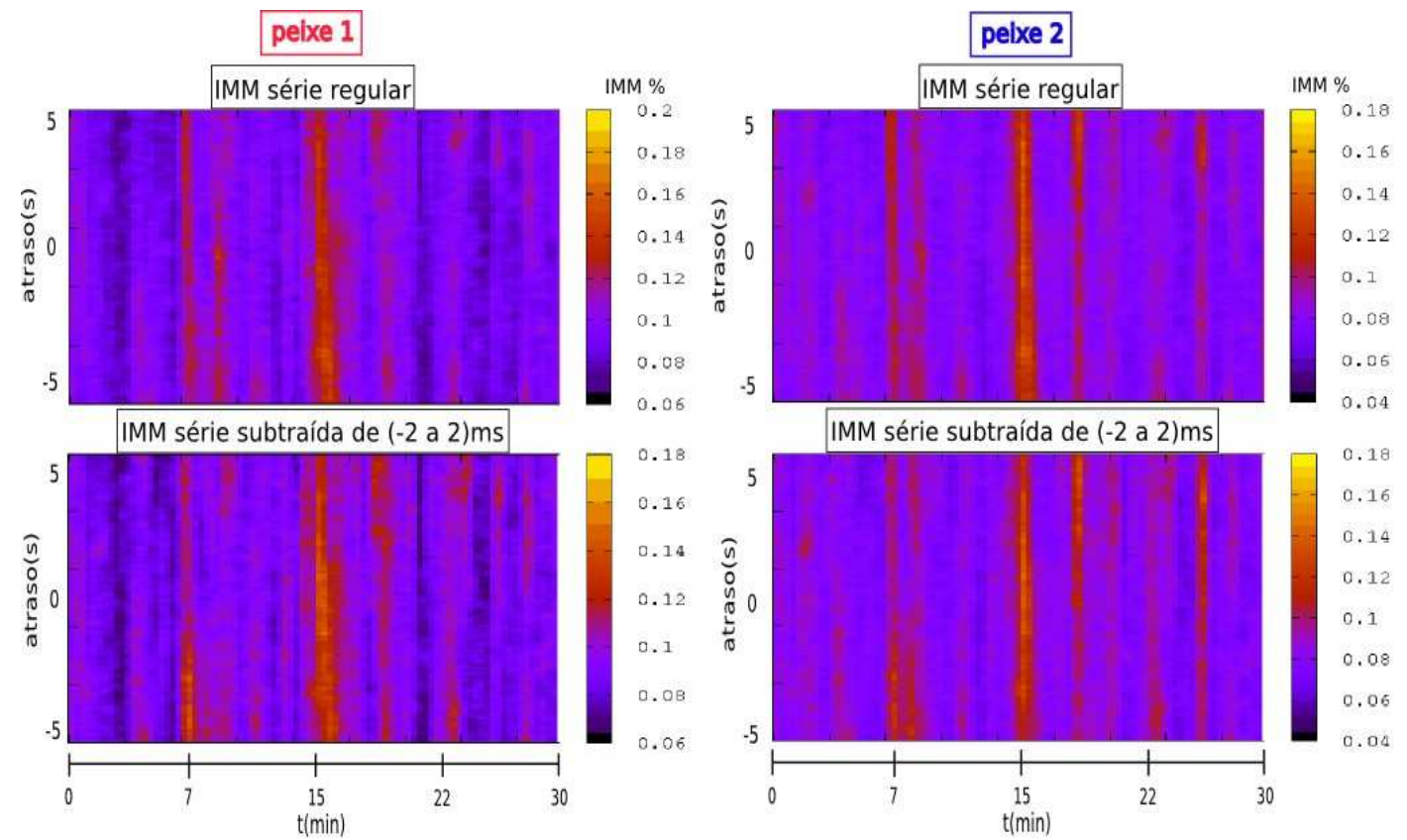

Figura 26 - IMM para série regular e para série que foi subtraída valores aleatórios num intervalo de (-2 a 2)ms. Os gráficos são muito semelhantes indicando que os peixes estão trocando algum tipo de informação que não provêm do JAR.

Os picos da IMM continuaram nos mesmos lugares, indicando que os peixes estão trocando algum tipo de informação que não provêm do JAR, mas sim, de algum tipo de comunicação social. 


\section{6 - Conclusões e discussões}

Desenvolvemos um aparato experimental que permitiu gravar os disparos do OE de peixes elétricos de campo fraco pulsadores da espécie Gymnotus carapo. Nosso aparato permite estimular o peixe e detectar seus disparos sem restringir seus movimentos dentro do tanque de experimento $(40 \mathrm{X} 40 \mathrm{X} 40) \mathrm{cm}$.

A partir de nossas medidas com diversos eletrodos é possível inferir a posição do peixe e relacionar seu movimento ao comportamento elétrico. Também desenvolvemos diversos circuitos eletrônicos e programas de controle e aquisição de dados em tempo real para permitir que estimulássemos os peixes produzindo pulsos idênticos aos de um peixe da mesma espécie mas com seqüência de ISIs determinada por computador. Em nossos estudos utilizamos seqüências aleatórias, realistas (gravadas do próprio ou de outros peixes) e também podemos conetar remotamente peixes em dois aquários diferentes em tempo real.

Nossas medidas longas, nas quais os peixes foram isolados de estímulos externos, revelaram que há variabilidade nos disparos do OE com grande diferenças entre dia e noite. $\mathrm{O}$ comportamento dos animais é relacionado com a dinâmica das descargas do OE: de dia o peixe fica mais tempo parado, possivelmente dormindo, e a variabilidade dos ISIs é menor; já de noite, há movimentação intensa do animal e a variabilidade dos ISIs é grande e é proporcional à amplitude da variação de sua posição.

Os peixes reagem ao serem estimulados, eles se movimentam mais, aumentam a frequiência de disparos do $\mathrm{OE}$, assim como, sua variabilidade. Há indícios de que eles reconhecem a diferença entre um estímulo com sequiência de ISIs de um peixe e um com seqüência aleatória: no estímulo aleatório o peixe responde com ISIs de menor variabilidade e diminui sua freqüência de DOE, indicando que o peixe está mais relaxado. Este estímulo foi o único que causou um comportamento semelhante aquele no qual o peixe estava sem estímulo.

Os peixes "reconhecem" padrões nos estímulos, mesmos quando estes são apresentados sem ordem causal. Entretanto, as respostas dadas a esses estímulos variam enormemente de animal para animal e também quando um estímulo é apresentado em dias diferentes para o mesmo animal.

Os padrões nos estímulos que são reconhecidos, não apresentam semelhanças entre si nem outras características facilmente identificáveis, tampouco as respostas dadas a eles. O único difencial destes trechos com alta IMM é que eles apresentam ISIs com grande variabilidade, condição necessária mas não suficiente para haver picos na IMM.

Adicionando ruído aos tempos de disparo verificamos que os picos de IMM não são devidos ao mecanismo de JAR mas sim à troca de informação por algum tipo de comunicação social.

No futuro pretendemos ampliar o estudo iniciado neste trabalho principalmente de três maneiras: (a) realizar experimentos sistemáticos para procurar encontrar os padrões usados na comunicação entre os peixes; (b) introduzir alterações nas amplitudes dos pulsos de estímulo para simular situações mais realistas como aproximação e afastamento do "peixe-estímulo"; (c) estudar alterações nos padrões de comportamento elétrico dos peixes devidas à alterações no meio ambiente como, por exemplo, a presença de impurezas na água. 


\section{7 - Referências}

Assad, C. A., Rasnow, B., Stoddard, P. K. (1999): Electric organ discharges and electric images during electrolocation. J. Exp. Biol. 202, 1185-1193.

Baffa, O., Côrrea, S. L. (1992): Magnetic and electric characteristics of the electric fish Gymnotus carapo. Biophys. J. 63, 591-593.

Bennet, M. V. L., Grundfest, H. (1959): Electrophysiology of electric organ in Gymnotus carapo. J. Gen. Physiol 42, 1067-1104.

Borst, A. e Theunissen, F. E. (1999): Information theory and neural coding, Nature Neurosci. 2, 947-957.

Bullock, T. H. (1999): The future of research on electroreception and electrocommunication. J. Exp. Biol. 202, 1455-1458.

Bullock, T. H., Fernandes-Souza, N., Graf, W., Helligenberg, W., Langner, G., Meyer, D. L., PimentelSouza, F., Scheich, H., Viancour, T. A. (2006): Aspectos do uso da descarga do órgão elétrico e eletrorrecepção nos Gymnotoidei e outros peixes amazônicos. http://www.icb.ufmg.br/lpf/1-11.html, acessado em 03/04/2006.

Capurro, A., Macadar, O., Perrone, R., Pakdaman, K. (1998): Computational model of the jamming avoidance response in the electric fish Gymnotus carapo. BioSystems. 48, 21-27

Capurro, A., Malta, C. P. (2004): Noise autocorrelation and jamming avoidance performance in pulse type electric fish. Bull. Math. Biol. 66, 885-905.

Caputi, A., Budelli, R. (1995): The electric image in weakly electric fish: I. A data-based model of waveform generation in Gymnotus carapo. J. Comput. Neurosci. 2, 131-147.

Caputi, A. A. (1999): The electric organ discharge of pulse gymnotiforms: thetransformation of a simple impulse into a complex spatio-temporal electromotor pattern. J. Exp. Biol. 202, 1229-1241.

Caputi, A. A., Aguilera, P.A., Castelló, M. E. (2003): Probability and amplitude of novelty resposes as a function of the change in contrast of the reafferent image in G. Carapo. J. Exp. Biol. 206, 999-1010.

Castelló, M. E., Aguilera, P.A., Trujillo-Cenóz, O., Caputi, A.A. (2000): Electroreception in Gymnotus carapo: pre-receptor processing and the distribution of electroreceptor types. J. Exp. Biol. 203, 3279-3287.

Chacron, M. J. (2006): Nonlinear information processing in a model sensory system. J. Neurophysiol., Articles in Press. (February 22, 2006) doi:10.1152/jn.01296.2005.

DeCoursey, P. J. (1993): Sensory perception and communication in electric fish. In Tested studies for laboratory teaching, vol. 5, (C.A. Goldman, P.L.Hauta, M.A. O'Donnell, S. E. Andrews, and R. van der Heiden, Editors). Proceedings of the $5^{\text {th }}$ Workshop/Conference of the Association for Biology Laboratory Education (ABLE). http://www.zoo.utoronto.ca/able.

von der Emde, G. (1999): Active electrolocation of objects in weakly electric fish. J. Exp. Biol. 202, 1205-1215.

Fortune, E. S., Rose, G. J., Kawasaki, M. (2006): Encoding and processing biolocally relevant temporal information in electrosensory systems. J. Comp. Physiol. A, Articles in Press., DOI 10.1007/s00359-006-0102-0. 
Mainen, Z. F. and Sejnowski, T. (1995), Reliability of spike timing in neocortical neurons. Science 268, 1503-1508.

Moortgat, K. T., Bullock, T. H., Sejnowski, T. J. (2000): Precision of the pacemaker nucleus in a weakly electric fish: network versus cellular influences. J. Neurophysiol. 83, 971-983.

Moortgat, K. T., Keller, C. H., Bullock, T. H., Sejnowski, T. J. (1998): Submicrossecond pacemaker precision is behaviorally modulated: the gymnotiform electromotor pathway. Proc. Natl. Acad. Sci. USA 95, 4684-4689.

Panzeri,S. and Treves, A. (1996): Analytical estimates of limited sampling biases in different information measures . Computation in Neural Systems 7, 87-107.

Rabinovich, M. I., Pinto, R. D., Abarbanel, H. D. I., Tumer, E. , Stiesberg, G. , Huerta, R., and Selverston, A. I. (2002), Recovery of hidden information through synaptic dynamics, Network: Comput. Neural Syst. 13, 487-501.

Rieke, F., Warland, D., van Steveninck, R. R. e Bialek, W. (1997): Spikes - Exploring the neural code, MIT press, London, England.

Rinzel, J. e Ermentrout, G. B. (1998): Analysis of neural excitability and oscillations. Em: Methods in Neuronal Modelling, eds. C. Koch e I. Segev, MIT Press, Cambridge, MA.

Roulston, M. S.(1999):Estimating the errors on mesured entropy and mutual information, Phisica D125, 285-294.

Santana, U. J., Roque-da-Silva, A. C., Duarte, T. T., and Corrêa, S. A. L. (2001): Interference with the GABAergic system in the dorsolateral telencephalon and modulation of the electric organ discharge frequency in the weakly electric fish Gymnotus carapo. J. Comp. Physiol. A 187, 925-933.

Shannon, C. E. (1948): The mathematical theory of communication, Bell Syst. Tech. J. 27, 379-423.

Stopa, R. M., Hoshino, K. (1999): Electrolocation-communication discharges of the fish Gymnotus carapo L. (Gymnotidae: Gymnotiformes) during behavioral sleep. Braz. J. Med. Biol. Res. 32, 1223-1228.

Takizawa, Y., Rose, G. J., Kawasaki, M. (1999): Resolving competing theories for control of the jamming avoidance response: the role of amplitude modulations in electric organ discharge decelerations. J. Exp. Biol. 202, 1377-1386.

Tan, E. W., Nizar, J. M., Carrera-G, E., Fortune, E. S. (2005): Electrosensory interference in naturally occurring aggregates of a species of weakly electric fish, Eigenmannia virescens. Behav. Brain Res. 164, 83-92.

Theiler, J., Eubank, S., Longtin, A., Galdrikian, B., and Farmer, J. D. (1992) Testing for nonlinearity in time series: the method of surrogate data. Physica D 58, 77-94.

Trujillo-Cenóz, O., Echagüe, J. A., Macadar, O. (1984): Innervation pattern and electric organ discharge waveform in Gymnotus carapo (Teleostei; Gymnotiformes). J. Neurobiol. 15, 273-281.

Westby, G.W.M. (1975): Comparative studies of the aggressive behaviour of two Gymnotid electric fish (Gymnotus carapo and Hypopomus artedi). Anim.Behav. 23, 192-213. 


\section{8 - Apêndices}

\section{A1 - Teoria da Informação}

Ao olhar o histograma bidimensional da IMM procuramos picos relevantes que representem os trechos das séries de estímulo e resposta correspondentes ao máximo processamento de informação entre os dois peixes.

O cálculo é sensível à escolha à escolha do tamanho do $\Delta \mathrm{t}$ e à escolha do número $\mathrm{n}$ de bits em cada palavra que determina a estatística diretamente, pois define o número de eventos possíveis, supondo que a distribuição das palavras é uniforme, então se a palavra tem $\mathrm{n}$ bits então existem $2 \mathrm{n}$ palavras possíveis, e a matriz de probabilidades conjuntas tem $2^{2 \mathrm{n}}$ elementos.

Escolhemos palavras de 8 bits, $\mathrm{n}=8$, então a matriz de probabilidades conjuntas tem $2^{2 \mathrm{n}}=2^{16}=65536$ posições.

Nos cálculos iniciais da IMM, foi escolhida uma janela de 4min ( 14000 bits) para que obtivéssemos uma boa estatística mas os gráficos apresentaram picos de IMM muito baixos. Como o tempo de reação do peixe é rápido, depois de 4 min os estímulos não estão mais relacionados, ou seja, não existe mais troca de informação entre as séries ocasionando picos de IMM com valores muito baixos. Então diminuímos o tamanho da janela para um valor mais razoável comparado ao tempo de reação do peixe mas que não fosse tão pequena para que ainda estivéssemos uma estatística relevante.

O cálculo da IMM foi feito em janelas de 40s que contém aproximadamente 2500 bits, então temos um conjunto de 2500-7 palavras/janela, o que é significativo pois a distribuição das palavras não é uniforme, muitas palavras são muito repetidas enquanto outras acontecem muito pouco, desse modo não precisamos de uma janela muito grande que contenha todas as ocorrências de palavras possíveis para popular toda matriz de probabilidades conjuntas (Panzeri e Treves, 1996)(Roulston, 1999).

O número de bits de uma palavra influi diretamente na estatística, uma vez que altera o número de possibilidades da matriz de probabilidades conjuntas, como a escolha de número de bits $(\mathrm{n}=8)$ de uma palavra foi arbitrária, fizemos cálculos da IMM para palavras com um número menor de bits $\mathrm{n}=4$ (figura $\mathrm{A} 1$ ), onde, são necessárias 256 palavras para popular toda a matriz, desse modo com a janela de 40s é possível popular a matriz quase 10 vezes e também refizemos os cálculos para $\mathrm{n}=5$ (figura A1), $2^{2 \mathrm{n}}=1024$, onde é possível popular a matriz quase 3 vezes. Os gráficos de IMM apresentaram resultados coerentes e semelhantes entre si. 


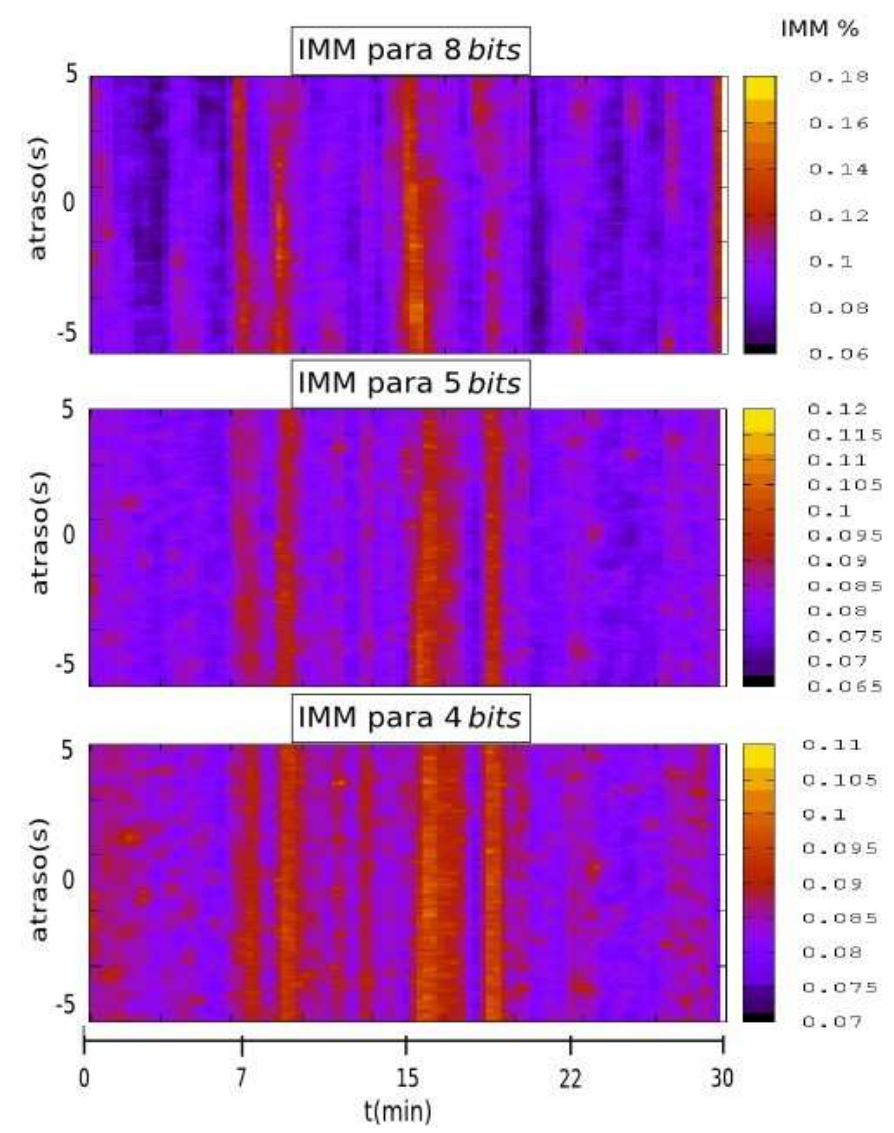

Figura A1 - IMM para palavras com número de bits diferentes. 


\section{A2- Método dos surrogados}

Para verificar a significância estatística de nossos resultados do cálculo da informação mútua média utilizamos o método dos surrogados (Theiler et al., 1992). Em nosso caso utilizamos um tipo de surrogado em que embaralhamos aleatoriamente os estímulos do conjunto de pares (s,r) em cada janela, quebrando a relação de causalidade entre os membros de um par, e recalculamos a informação mútua média (IMMsurr). Para verificar se a IMM dos pares originais é realmente relevante subtraímos dela a IMMsurr obtida com os pares surrogados e procuramos por picos persistentes de IMM (figura A2).
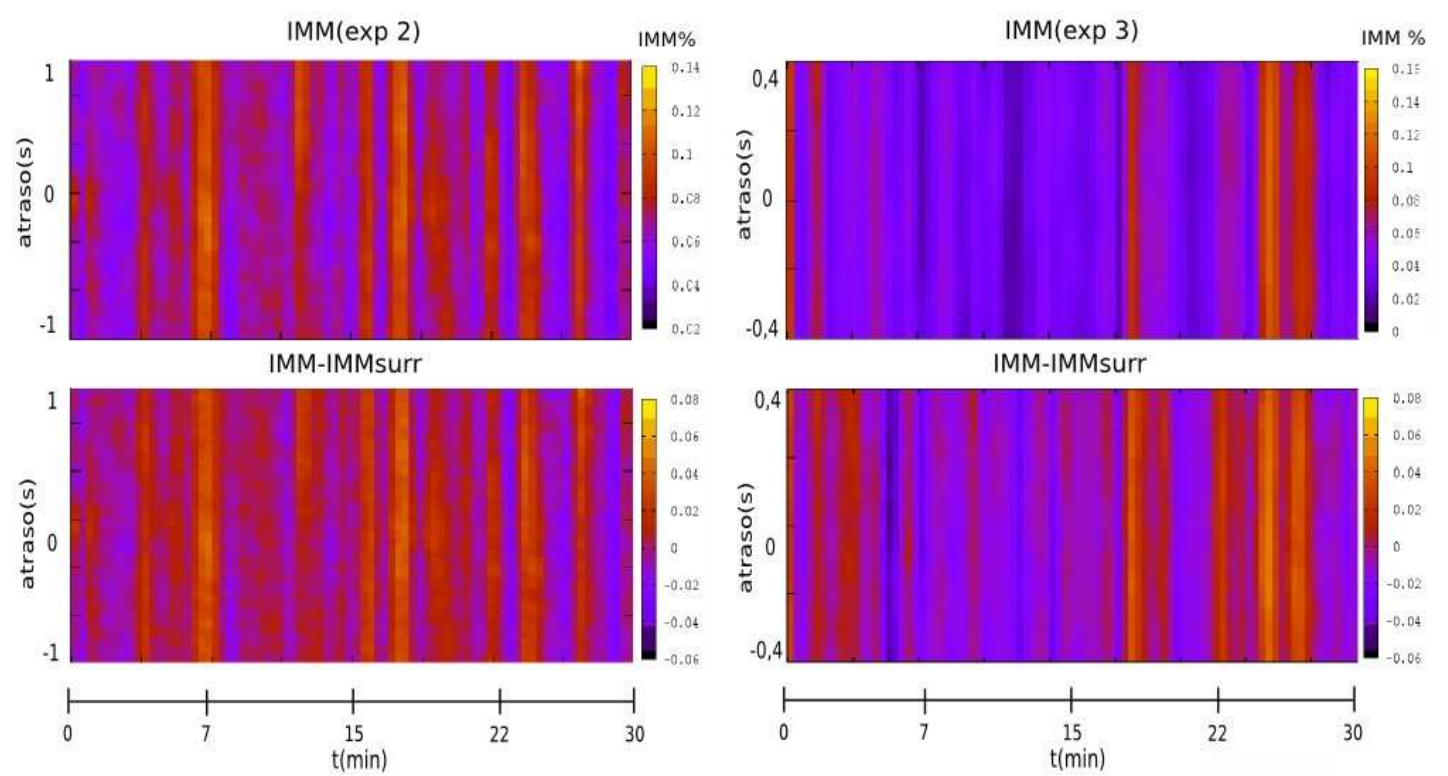

Figura A2 - IMM e surrogado subtraído da IMM. À esquerda: série de estímulos de DOEs de um peixe previamente gravado (experimento 2, seção 5.2) e à direita: experimento 3 , seção 5.3, na qual dois peixes estão interagindo.

Nota-se que após a subtração, ainda há picos e estes continuaram nos mesmos lugares, indicando que realmente existe informação sendo transmitida entre os estímulos e as respostas. 